\title{
THE
}

1998

\section{A Numerical Simulation of the Mean Water Pathways in the Subtropical and Tropical Pacific Ocean}

\author{
Lewis M. Rothstein \\ University of Rhode Island, Irothstein@uri.edu \\ Rong-Hua Zhang \\ University of Rhode Island \\ Antonio J. Busalacchi \\ Dake Chen
}

Follow this and additional works at: https://digitalcommons.uri.edu/gsofacpubs

\section{Citation/Publisher Attribution}

Rothstein, L. M., \& Zhang, R-H. (1998). A Numerical Simulation of the Mean Water Pathways in the Subtropical and Tropical Pacific Ocean. J. Phys. Oceanogr., 28, 322-343. doi: 10.1175/ 1520-0485(1998)0282.0.CO;2.

Available at: https://doi.org/10.1175/1520-0485(1998)028<0322:ANSOTM>2.0.C0;2

This Article is brought to you for free and open access by the Graduate School of Oceanography at DigitalCommons@URI. It has been accepted for inclusion in Graduate School of Oceanography Faculty Publications by an authorized administrator of DigitalCommons@URI. For more information, please contact digitalcommons-group@uri.edu. 


\title{
A Numerical Simulation of the Mean Water Pathways in the Subtropical and Tropical Pacific Ocean
}

\author{
Lewis M. RothsteIn AND Rong-HuA ZHANG \\ Graduate School of Oceanography, University of Rhode Island, Narragansett, Rhode Island \\ ANTONIO J. BUSALACCHI \\ Laboratory for Hydrospheric Process, NASA/Goddard Space Flight Center, Maryland \\ DAKe Chen \\ Lamont-Doherty Earth Observatory, Palisades, New York \\ (Manuscript received 28 June 1996, in final form 30 June 1997)
}

\begin{abstract}
A reduced-gravity, primitive-equation, upper-ocean general circulation model is used to study the mean water pathways in the North Pacific subtropical and tropical ocean. The model features an explicit physical representation of the surface mixed layer, realistic basin geometry, observed wind and heat flux forcing, and a horizontal grid-stretching technique and a vertical sigma coordinate to obtain a realistic simulation of the subtropical/ tropical circulation. Velocity fields, and isopycnal and trajectory analyses are used to understand the mean flow of mixed layer and thermocline waters between the subtropics and Tropics.

Subtropical/tropical water pathways are not simply direct meridional routes; the existence of vigorous zonal current systems obviously complicates the picture. In the surface mixed layer, upwelled equatorial waters flow into the subtropical gyre mainly through the midlatitude western boundary current (the model Kuroshio). There is additionally an interior ocean pathway, through the Subtropical Countercurrent (an eastward flow across the middle of the subtropical gyre), that directly feeds subtropical subduction sites. Below the mixed layer, the water pathways in the subtropical thermocline essentially reflect the anticyclonic gyre circulation where we find that the model subtropical gyre separates into two circulation centers. The surface circulation also features a doublecell pattern, with the poleward cell centered at about $30^{\circ} \mathrm{N}$ and the equatorward component contained between $15^{\circ}$ and $25^{\circ} \mathrm{N}$. In addition, thermocline waters that can be traced to subtropical subduction sites move toward the Tropics almost zonally across the basin, succeeding in flowing toward the equator only along relatively narrow north-south conduits. The low-latitude western boundary currents serve as the main southward circuit for the subducted subtropical thermocline water. However, the model does find a direct flow of thermocline water into the Tropics through the ocean interior, confined to the far western Pacific (away from the low-latitude western boundary currents) across $10^{\circ} \mathrm{N}$. This interior pathway is found just to the west of a recirculating gyre in and just below the mixed layer in the northeastern Tropics. This equatorward interior flow and a flow that can be traced directly to the western boundary are then swept eastward by the deeper branches of the North Equatorial Countercurrent, finally penetrating to the equator in the central and eastern Pacific. Most of these results are consistent with available observations and recently published theoretical and idealized numerical experiments, although the interior pathway of subtropical thermocline water into the Tropics found in this experiment is not apparent in other published numerical simulations.

Potential vorticity dynamics are useful in explaining the pathways taken by subtropical thermocline water as it flows into the Tropics. In particular, a large-scale zonally oriented "island" of homogenous potential vorticity, whose signature is determined by thin isopycnal layers in the central tropical Pacific along about $10^{\circ} \mathrm{N}$, is dynamically linked to a circulation that does not flow directly from the subtropics to the Tropics. This largescale potential vorticity feature helps to explain the circuitous pathways of the subducted subtropical thermocline waters as they approach the equator. Consequently, waters must first flow westward to the western boundary north of these closed potential vorticity contours and then mostly move southward through the low-latitude western boundary currents, flow eastward with the North Equatorial Countercurrent, and finally equatorward to join the Equatorial Undercurrent in the thermocline.
\end{abstract}

\section{Introduction}

Although the ocean circulations in the subtropics and Tropics have been investigated separately by many (e.g.,

Corresponding author address: Dr. Rong-Hua Zhang, Graduate School of Oceanography, University of Rhode Island, Narragansett, RI 02882. E-mail: zrh@sequan.gso.uri.edu
Pedlosky 1990; Philander 1990), it was not until recently that their interactions have received significant attention (Pedlosky 1991b; McCreary and Yu 1992; McCreary and Lu 1994; Liu 1994; Liu et al. 1994; Lu and McCreary 1995; Pedlosky 1997). Subtropical/tropical water pathways are fundamentally defined by the basin-scale structure of the thermocline; the redistribution of mass, heat, and other properties by this circulation, in turn, changes the thermocline structure. One 
example of such a basin-scale pathway is a proposed subtropical/tropical water mass exchange whereby equatorward flow within the thermocline is compensated by poleward flow in the surface layers, closed by upwelling at the equator and subduction in the subtropics, the so-called "Subtropical Cell" (STC; McCreary and Lu 1994). Accompanying this cell would be a climatically important poleward heat transport by the warm surface waters, with colder thermocline water moving equatorward. For this reason, it is important to continue the critical examination of whether this, and other subtropical/tropical circulations exist.

Theoretical arguments have been advanced that attempt to construct a consistent dynamical framework for understanding subtropical/tropical circulations. The complexity in such a construction is high, demanding the proper representations of diverse dynamical regimes (e.g., eastern, western, equatorial, and surface boundary layers consistent with the interior domain). Most of these are based upon conservation of potential vorticity principles and can be classified as tropical extensions to the subtropical ventilated thermocline theory [see Pedlosky (1997) for a summary]. In such a theoretical framework, the Equatorial Undercurrent (EUC) is modeled as an inertial jet within an equatorial boundary layer. The solutions do predict a realistic EUC in the interior that is "driven" by subtropical subduction. However, these theories remain incomplete due to exclusion of explicit western and eastern boundary regimes as well as overly simplified mixed layer representations. In particular, the importance of including an explicit representation of the surface mixed layer has been successfully argued (Marshall and Nurser 1991; Williams 1991; Pedlosky and Robbins 1991). Indeed, active mixed layer dynamics and thermodynamics play an important role in intensifying subduction in that they allow lateral subduction, caused by spatial variations in the mixed layer depth, to sweep water around the subtropical gyre with much of this water simply returning poleward in the western boundary current when the subtropics are studied in isolation. When the Tropics are included, the resulting pathways will be considerably altered. Carefully designed numerical experiments are necessary to help unite the different dynamical domains in a consistent, basin-scale mapping.

Numerical experiments have been recently designed to address this problem (McCreary and Lu 1994; Liu 1994; Liu et al. 1994; Z. Liu, B. Huang, and N. Nasami 1996, personal communication). The earlier studies, with emphasis on physical understanding, employed idealized formulations of either the model geometry, model physics, or surface fluxes. Although quite useful in suggesting the fundamental physical processes of the subtropical/tropical interaction, details of the model water pathways (potentially important in quantifying global climate implications) were difficult to justify against the observational database due to unrealistic, or even missing, components of the model circulation (e.g., the
North Equatorial Countercurrent). More recently, Lu and McCreary (1995) sought to improve upon these earlier studies by studying the results from a $2 \frac{1}{2} 2$-layer model forced by observed climatological wind stress (but no heat fluxes) in a still idealized, but reasonably realistic, basin geometry. The upper layer represented the mixed layer and mixing was parameterized according to entrainment and subduction rates that were related to prespecified values of the entrainment depth; essentially a "switch" that turns entrainment either on or off depending upon the depth of the upper layer. Although the model is quite coarse in the vertical and has this rather simple parameterized coupling of mixed layer processes with the thermocline, it does improve the previous numerical studies. Their solutions indicate that all subtropical/tropical gyre exchanges are routed through the low-latitude western boundary current (LLWBC) region.

Observations of the complete subtropical/tropical North Pacific ocean circulations are difficult to come by, but those that do exist have been valuable in verifying these theoretical studies and model simulations (Wyrtki 1975; Fine et al. 1981; Wyrtki and Kilonsky 1984; Fine 1987; Talley 1988; McPhaden and Fine 1988; Tsuchiya et al. 1989; Lukas et al. 1991). Especially important are direct current measurements that show an equatorial convergence of tropical thermocline water and a poleward, surface Ekman drift in the central Pacific (Firing et al. 1981; Luther and Johnson 1990; Qiao and Weisberg 1996). Subtropical water has also been identified within the tropical thermocline (Bryden and Brady 1985; Quay et al. 1983; Roemmich 1987; Tsuchiya et al. 1989). In particular, McPhaden and Fine (1988) use the observed tritium distribution to suggest that there is convergence of subtropical water in the central and eastern equatorial Pacific, associated with interior water pathways that are isolated from western boundary current regions. The observational picture is maturing to the point where realistically designed numerical experiments can be useful. Thus, we are now at the beginning stages of interrogating these numerical simulations to obtain a more detailed dynamic and kinematic understanding of the pathways taken by water particles during their excursions between the subtropics and Tropics.

For a more realistic simulation of the North Pacific subtropical-tropical circulations, a model should be capable of reasonably reproducing the thermal structure and circulation, especially within the well-mixed surface layer and the stratified thermocline, the LLWBC, and the North Equatorial Countercurrent (NECC). Toward this end, we use a mature reduced-gravity, general circulation model that explicitly represents the dynamics and thermodynamics of the mixed layer (Chen et al. 1994a,b). The present study seeks to improve on Lu and McCreary (1995) by including explicit mixed layer physics that better resolve the exchange of water between the mixed layer and the thermocline. In addition, realistic basin geometry and heat flux forcing are included. 
A more complete description of the model is given in section 2, together with its numerical implementation. The simulated mean North Pacific subtropical/tropical circulations and water pathways are presented in section 3 , which are then further examined on isopycnal surfaces in section 4 . Section 5 summarizes the results.

\section{Model description}

The ocean model consists of two main components: a sigma-layer, tropical circulation model developed by Gent and Cane (1989), and a mixed-layer model that was developed to properly account for the different mechanisms by which the ocean mixed layer communicates with both the upper thermocline and the overlying atmosphere (Chen et al. 1994a,b). The mixing scheme is capable of simulating the three major mechanisms of turbulent vertical mixing in the upper ocean: wind stirring, shear instability, and convective overturning. Because of the inclusion of all these mixing algorithms, the model is equally suited for application to both the subtropics (where direct wind stirring is expected to dominate the mixing) and the Tropics (where mixing due to shear instability cannot be neglected). Basically, the mixed layer model combines the best features of the Kraus and Turner (1967) bulk mixed layer formulation with an instability mixing model that is based upon a critical Richardson number. Convective overturning is instantaneous; the model is hydrostatic. See Chen et al. (1994a) for more details.

The vertical structure of the model ocean consists of discrete layers. The uppermost layer represents the mixed layer, and the layers below are chosen according to a sigma coordinate. Thus, the thickness of all layers are allowed to change, but the ratio of each sigma layer to the total water column below the mixed layer is fixed to its prescribed value. Once the mixed layer depth is predicted (prognostically by the aforementioned mixed layer model), the thickness of the remaining layers are calculated diagnostically. One of the advantages of such a vertical coordinate system is its computational efficiency. Furthermore, the vertical resolution can be high precisely where it is needed: right below the mixed layer and in the thermocline where shear-generated turbulence might be active. In the horizontal, in order to resolve the narrow current systems in the equatorial waveguide and the western boundary region, a grid-stretching technique is adopted.

The original tropical Pacific model (Chen et al. 1994b) is extended to cover the entire subtropical/tropical Pacific and Indian Oceans; however, we do not allow any Indo-Pacific ocean communication via the Indonesian Throughflow in the present study. The model land boundaries are taken roughly along the $200-\mathrm{m}$ isobath. The model upper ocean has an average depth of about $700 \mathrm{~m}$ for approximately representing the upper North Pacific Ocean and is divided into 11 layers. Observations have shown that the North Pacific subtropical gyre mainly lies within the upper $700 \mathrm{~m}$ (Levitus 1982), and water exchanges between the subtropics and the Tropics occurs mainly at shallower depths. Thus, the present model formulation, which allows for changes of the total vertical thickness, can well represent the subtropical gyre in the region. In the horizontal, the grid is stretched to achieve about $0.3^{\circ}$ resolution near the equator, with a maximum of $1^{\circ}$ resolution at $50^{\circ} \mathrm{N}$ and $50^{\circ} \mathrm{S}$. The zonal grid spacing is about $0.3^{\circ}$ near the western Pacific boundary and Indonesian archipelago regions, and about $1^{\circ}$ in the ocean interiors.

The model ocean is initially at rest, with initial temperature, salinity, and layer thicknesses taken from the annual mean Levitus (1982) data. The horizontal boundary conditions are no slip and no flux. To minimize the artificial effects of the closed southern and northern boundaries at $50^{\circ} \mathrm{S}$ and $50^{\circ} \mathrm{N}$, the model temperature, salinity, and layer thickness are gradually relaxed to the seasonally varying Levitus climatology poleward of $45^{\circ} \mathrm{N}(\mathrm{S})$. The model is forced with the seasonal varying wind stress of Hellerman and Rosenstein (1983), heat fluxes are calculated according to Seager et al. (1988), and surface salinity is relaxed to the Levitus data. The model is integrated for 15 years, by which time a reasonable equilibrium seasonal cycle has been established. The results to be analyzed are annual averages (hereafter identified as the mean) taken from the last model year.

\section{The simulated mean subtropical-tropical circulations}

Figure 1 shows the simulated mean sea surface temperature (SST), salinity (SSS), and total mass transport streamfunction $\psi$ defined as

$$
\psi_{x}=\sum_{k=1}^{K} h_{k} v_{k}, \quad \psi_{y}=-\sum_{k=1}^{K} h_{k} u_{k},
$$

where $k=1, \cdots, K$ are model layers in the vertical; $u$ and $v$ are the horizontal velocity; and $h$ is the layer thickness. The SST and SSS fields are in good agreement with the corresponding climatology, including the warm water pool in the tropical western Pacific, the tongue of cold surface water extending westward from the South American coast along the equator, strong SST gradients in high latitude regions, and the subtropical SSS maxima. We begin by first dividing the discussion into regional descriptions of the major features of the simulated mean circulations, and then we pull these together to describe the basin-scale pathways.

\section{a. The North Pacific Ocean circulation}

The main circulation gyres are clearly present in Fig. 1b. The dominant features are the subtropical anticyclonic gyres in both hemispheres, which extend across the basin and are intensified along the western boundary. The total mass transport is about $50 \mathrm{~Sv}$ in the North Pacific subtropical gyre, which consists of the model Kuroshio, the 


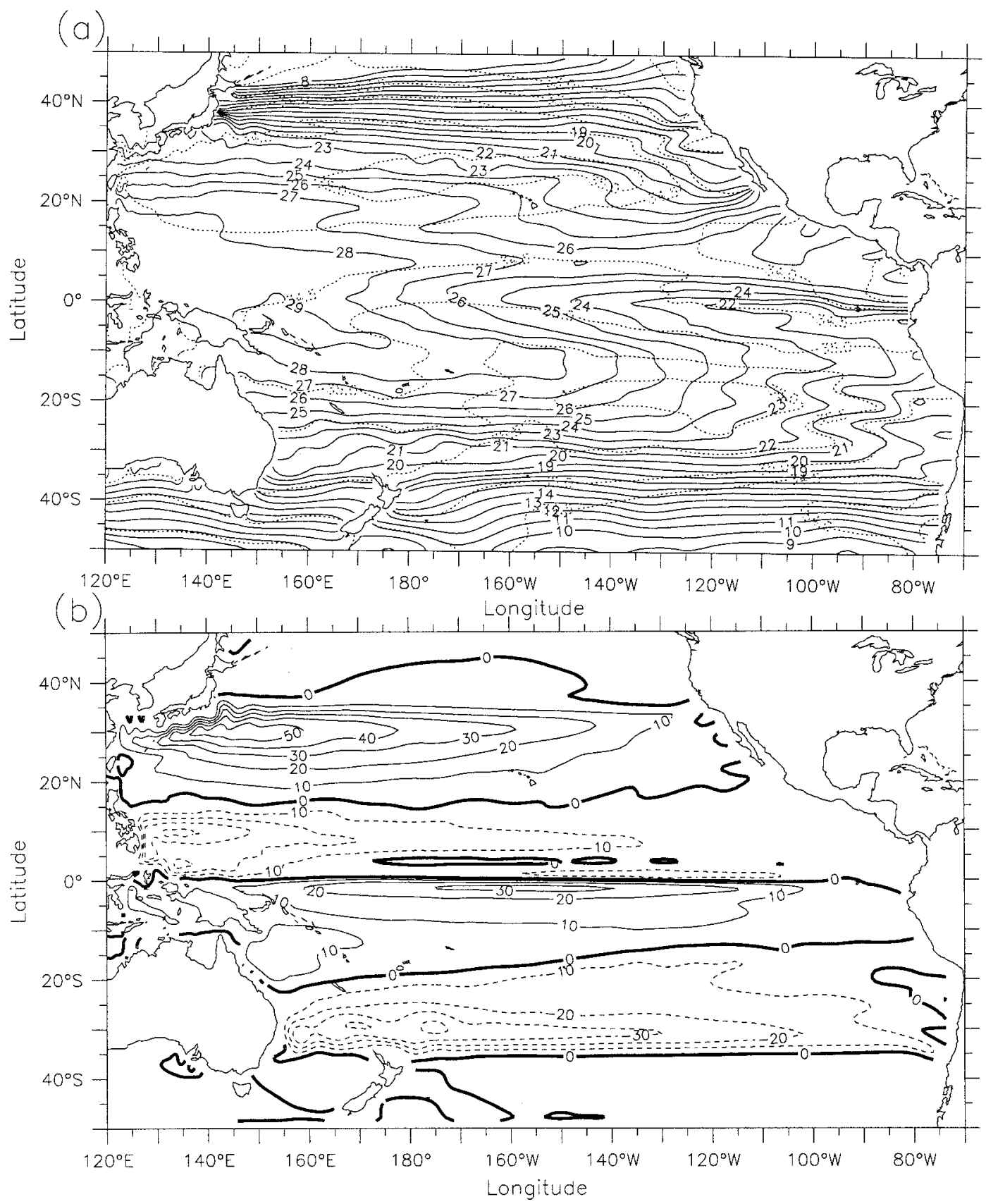

FIG. 1. (a) The model domain analyzed in this study and simulated mean mixed layer temperature (solid line) and salinity (dotted line) and (b) water mass transport streamfunction of layer integrated velocity over the entire model depth. The contour intervals are $1^{\circ} \mathrm{C}$ for temperature, $0.5 \mathrm{ppm}$ for salinity, and $10 \mathrm{~Sv}$ for streamfunction.

North Pacific Current (the Kuroshio Extension), the eastern boundary current system, and the North Equatorial Current (NEC). A cyclonic gyre is located in the western tropical Pacific region, with a total transport of $30 \mathrm{~Sv}$ that includes a vigorous model LLWBC region.

Figures 2 and 3 show horizontal maps of various simulated mean fields: mixed layer depth (Fig. 2a) and density (Fig. 2b), mass transport streamfunction calculated separately for the mixed layer (Fig. 2c) and for layers below
(Fig. 2d), sea surface elevation and surface current vectors (Fig. 3a), and potential vorticity and current vectors at 250-m depth (Fig. 3b). (Hereafter, we display only the domain north of $20^{\circ} \mathrm{S}$, as we are only interested in examining the North Pacific pathways for this paper.) The model reproduces known features of the large-scale ocean circulation and structure in the North Pacific subtropical/ tropical regions. In particular, as shown in the sea surface elevation (Fig. 3a), there is a double-cell subtropical cir- 

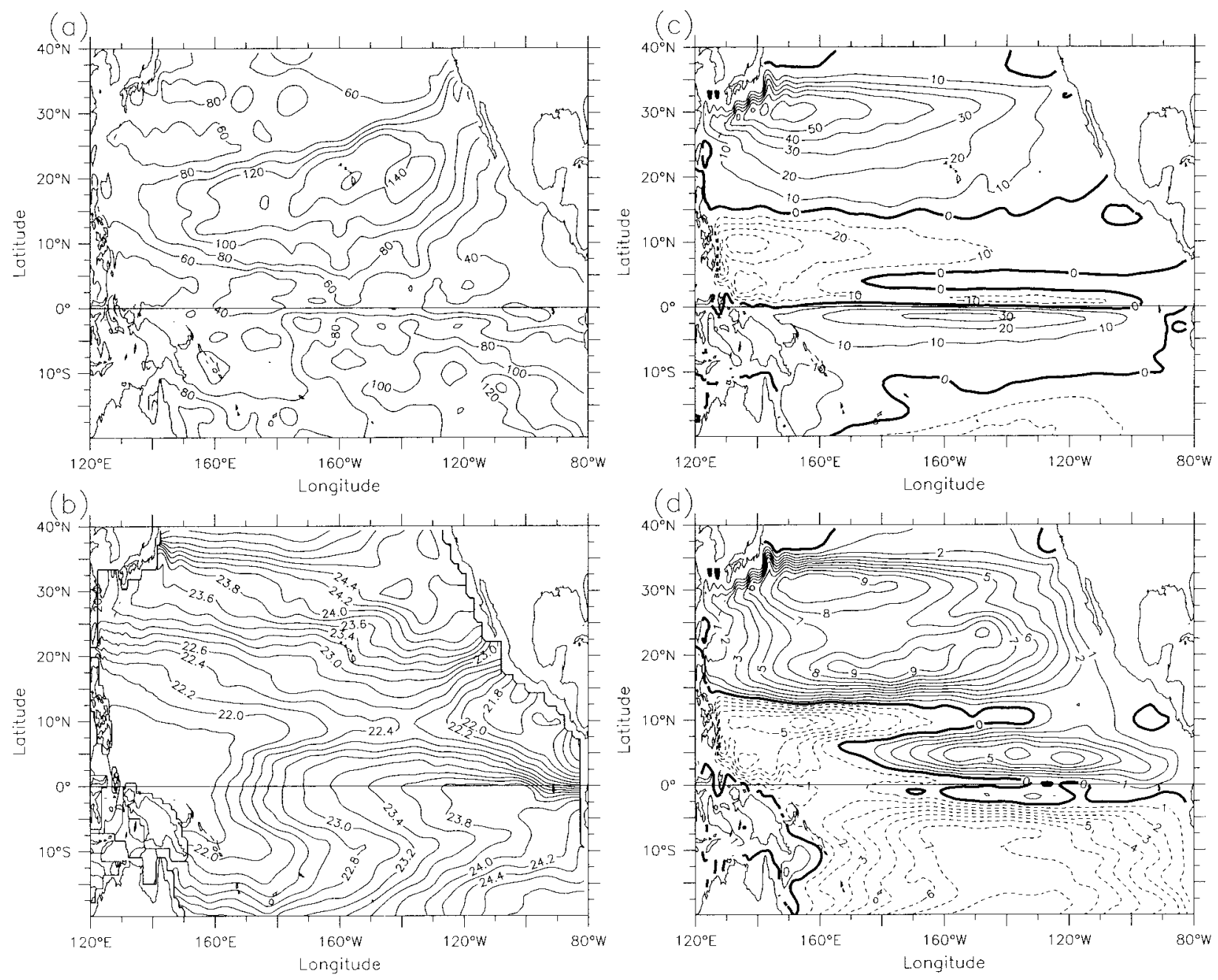

FIG. 2. The simulated annual-mean mixed layer depth (a), density (b), and mass transport streamfunction in the mixed layer (c), and below the mixed layer (d). The contour intervals are $20 \mathrm{~m}$ in (a), $0.2 \mathrm{~kg} \mathrm{~m}^{-3}$ in (b), $10 \mathrm{~Sv}$ in (c), and $1 \mathrm{~Sv}$ in (d).

culation pattern in the North Pacific, with the poleward cell centered at about $30^{\circ} \mathrm{N}$ and the equatorward component contained between $15^{\circ}$ and $25^{\circ} \mathrm{N}$. These two cells, separated by a prominent trough extending southwestward from the eastern boundary, both extend far eastward from the western boundary as a high pressure ridge. In addition, the main features of the circulation within the mixed layer and the thermocline can be clearly seen from the mass transport streamfunction (Figs. 2c,d). The similarity between Fig. 1b and Fig. 2c indicates that most of the winddriven North Pacific subtropical circulation and tropical western Pacific circulation occurs in the mixed layer. However, there are differences, especially in the central and eastern Tropics, indicating the importance of the significant circulations below the mixed layer. The thermocline circulation is dominated by four major gyres in the North Pacific (Fig. 2d). Among these, the subtropical gyre separates into two circulation centers. A fourth cyclonic gyre is found in the tropical northeastern Pacific; its mass transport maximum amplitude is about $6 \mathrm{~Sv}$.
Figure 3a presents the simulated ocean circulation in the surface mixed layer. The major current systems can be seen, including western boundary currents (the Kuroshio in midlatitude and the low-latitude Mindanao Current; see section 3c), the North Pacific current (the Kuroshio Extension), and the tropical currents (to be discussed fully in section 3b). Interestingly, the model also produces a predominantly eastward surface subtropical countercurrent (STCC) in the interior and eastern region between $20^{\circ}$ and $25^{\circ} \mathrm{N}$, where classic wind-driven circulation theory would predict a westward flow feeding the western boundary current. The existence of such a flow has been confirmed by both numerical studies and observations (e.g., Cushman-Roisin 1984), and is ascribed to a geostrophic adjustment to the zonal density front across the basin in the surface mixed layer (Fig. 2b).

The subsurface circulation (Fig. 3b) is dominated by geostrophic flow, coherent with the thermocline structure, that is, the potential vorticity $(Q)$ fields. For motion scales much larger than the Rossby deformation radius $(\sim 50$ 

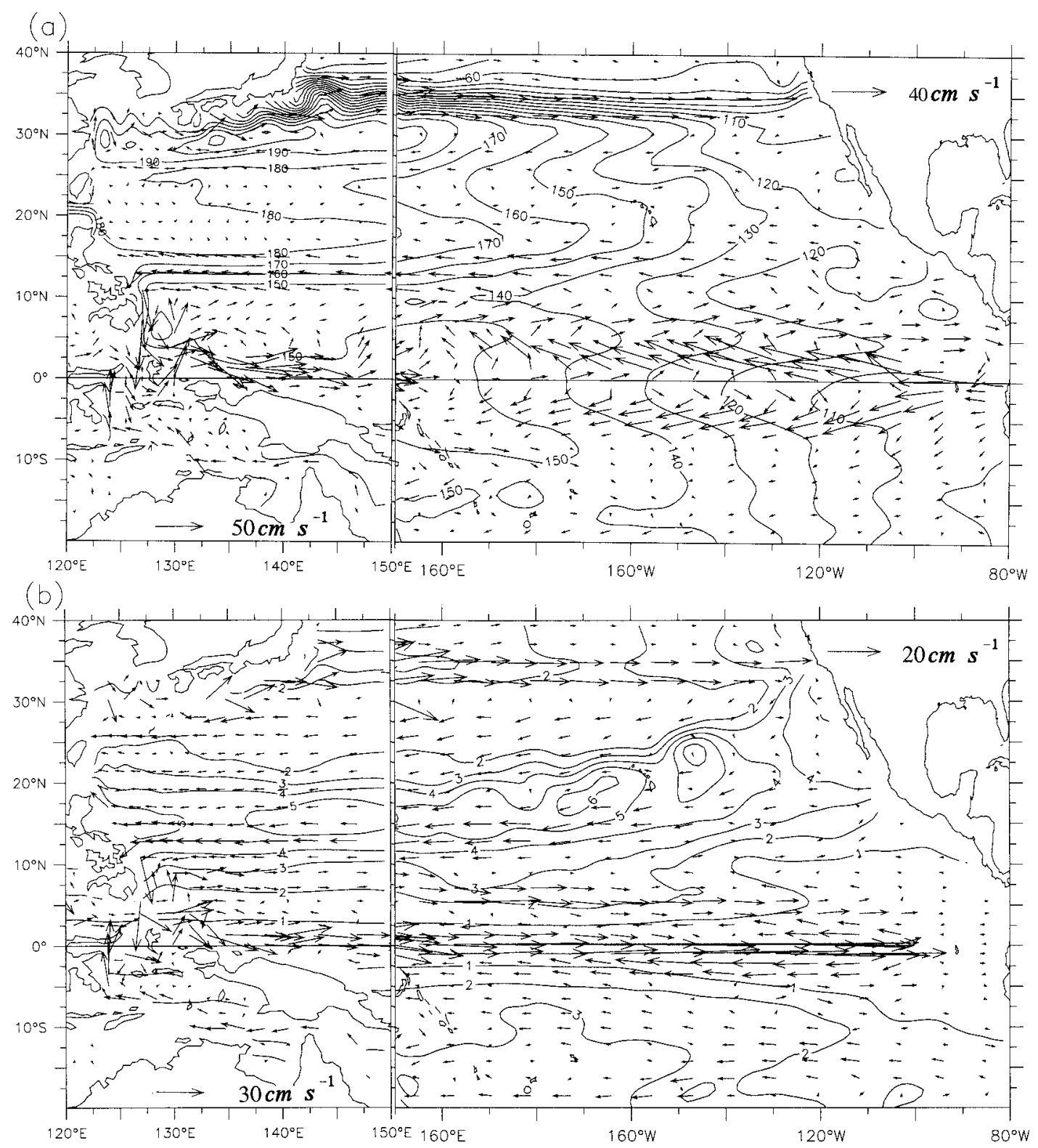

FIG. 3. The annual-mean sea level and mixed layer current vectors (a) and potential vorticity contours and current vectors at 250-m depth (b). The contour intervals are $10 \mathrm{~cm}$ in (a) and $1 \times 10^{-10} \mathrm{~m}^{-1} \mathrm{~s}^{-1}$ in (b). Note the stretched plotting in longitude for the western Pacific regions and different vector scales used in the figures.

$\mathrm{km}$ ), the relative vorticity is much smaller than the stretching vorticity so that $Q$ can be simply approximated as

$$
Q=\frac{f}{\rho_{0}} \frac{\Delta \rho}{\Delta Z}
$$

where $f$ is the Coriolis parameter, $\rho$ is in situ density, and $\Delta Z$ is the thickness between two density surfaces differing by $\Delta \rho$. The most striking characteristics evident in maps of this scalar field are well-defined, largescale patterns in the horizontal (Fig. 3b) as well as in the vertical (Figs. 4 and 5). A salient feature is a large spatial span of homogenous $Q$ in the latitude band between $25^{\circ}$ and $35^{\circ} \mathrm{N}$ within the subtropical gyre. To the southeast there are sharp $Q$ gradients that border extensive regions of closed $Q$ contours. In the northeastern Tropics, a $Q$-field trough is evident, extending from the eastern boundary into the central Pacific. In vertical section, the $Q$ structure is observed to have coherent changes from the northern to the southern part of the subtropical gyre, as well as from the western to eastern Pacific (Figs. 4 and 5). These $Q$ patterns, which basically define the basin-scale water pathways, are most re- 

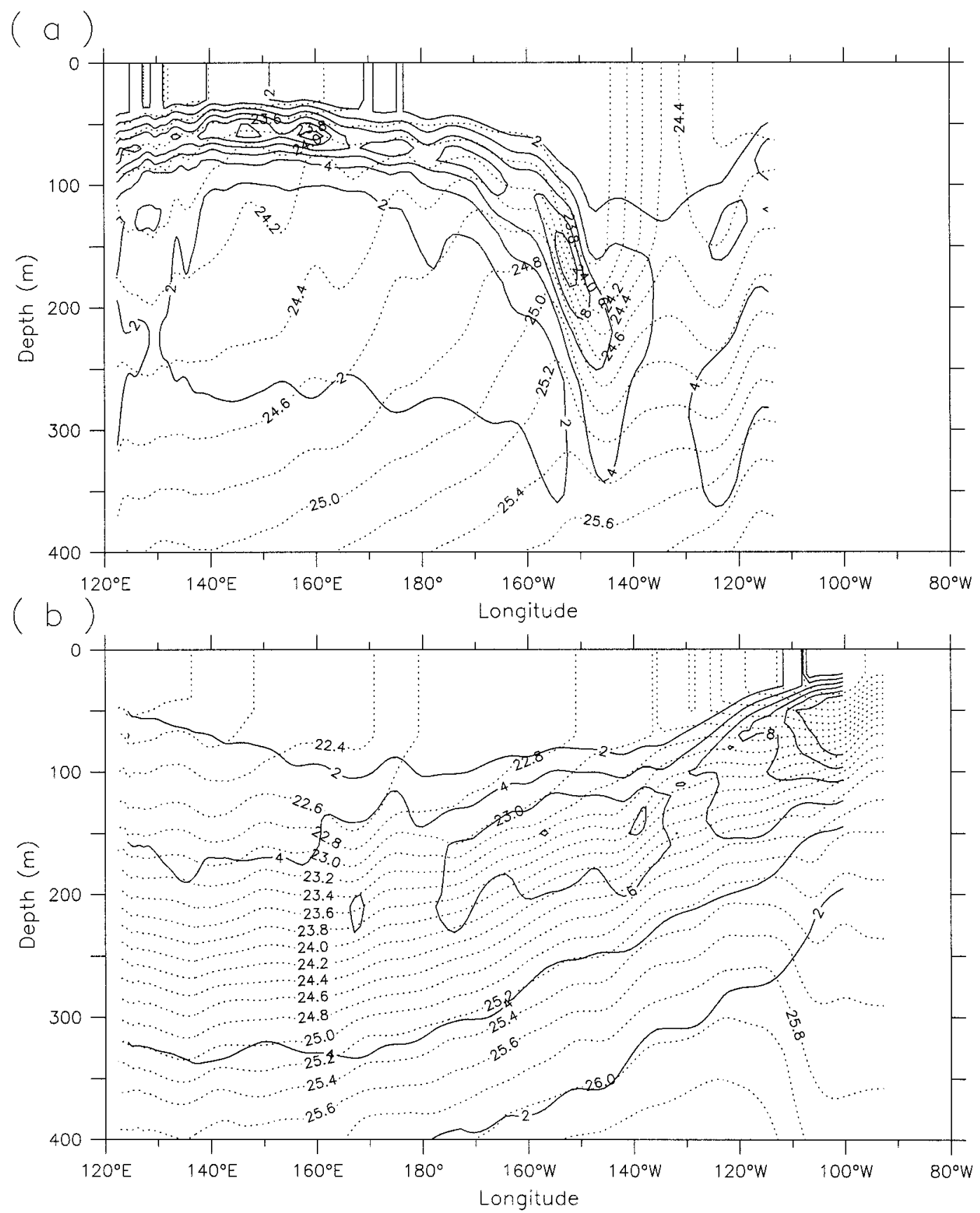

FIG. 4. Depth-longitude sections of potential vorticity (solid line) and density (dotted line) along (a) $25^{\circ}$ and (b) $15^{\circ} \mathrm{N}$, respectively. The contour intervals are $2 \times 10^{-10} \mathrm{~m}^{-1} \mathrm{~s}^{-1}$ for $Q$ and $0.5 \mathrm{~kg} \mathrm{~m}^{-3}$ for density.

vealing when analyzed along isopycnal surfaces and will be so discussed in section 4 .

\section{b. The tropical circulation}

As in a free surface ocean model (Zhang and Endoh 1992), the tropical trough-ridge structure in sea surface elevation can be clearly seen in Fig. 3a. In particular, there is a trough along $10^{\circ} \mathrm{N}$ that extends across the basin almost to the western boundary where the sea surface elevation falls below $140 \mathrm{~mm}$, where it is supported by a mean cyclonic recirculation (the model Mindanao eddy). On the southern flank of the southern part of the subtropical gyre along $15^{\circ} \mathrm{N}$, the NEC runs westward all the way across the basin to the western boundary. Also evident in the model simulation is the eastward North Equatorial Coun- 

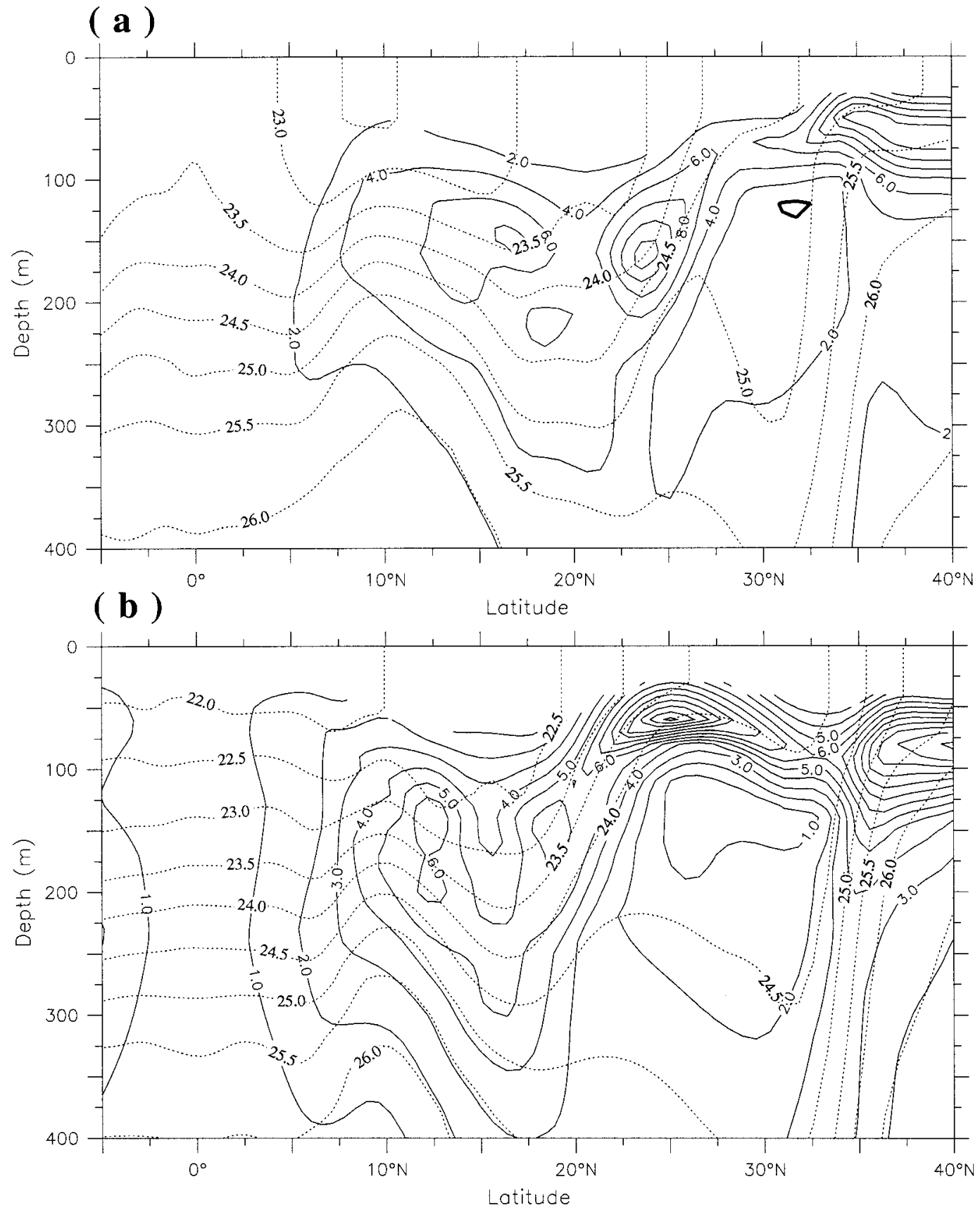

FIG. 5. Depth-meridional section of potential vorticity (solid line) and density (dotted line) along (a) $155^{\circ} \mathrm{W}$ and along (b) $160^{\circ} \mathrm{E}$, respectively. The contour intervals are $2 \times 10^{-10} \mathrm{~m}^{-1} \mathrm{~s}^{-1}$ for $Q$ and $0.5 \mathrm{~kg} \mathrm{~m}^{-3}$ for density.

tercurrent across the tropical Pacific along $8^{\circ}$ and $10^{\circ} \mathrm{N}$. South of the NECC, the South Equatorial Current (SEC) mostly prevails in the equatorial region.

Figure 6 presents the simulated total vertical velocity at the base of the surface mixed layer (Fig. 6a), a depthlongitude section of meridional velocity and temperature along $5^{\circ} \mathrm{N}$ (Fig. 6b), and depth-latitude sections of zonal velocity and temperature along $160^{\circ} \mathrm{E}$ (Fig. $6 \mathrm{c}$ ) and $155^{\circ} \mathrm{W}$ (Fig. 6d). A compelling feature is the well-organized struc- ture of the vertical, meridional, and zonal velocity fields. The vertical velocity at the base of the mixed layer is dominated by a strong, very narrow upwelling region confined to the equator of the central and eastern Pacific (about 5-6 $\mathrm{m} \mathrm{day}^{-1}$ in magnitude). On either side of the equator there are two bands of downwelling with the maximum located at $3^{\circ}$ and $4^{\circ} \mathrm{N}$ (about 3-4 $\mathrm{m} \mathrm{day}^{-1}$ ). These vertical velocities are important components of equatorial cells that involve both mixed layer and thermocline waters (Mc- 

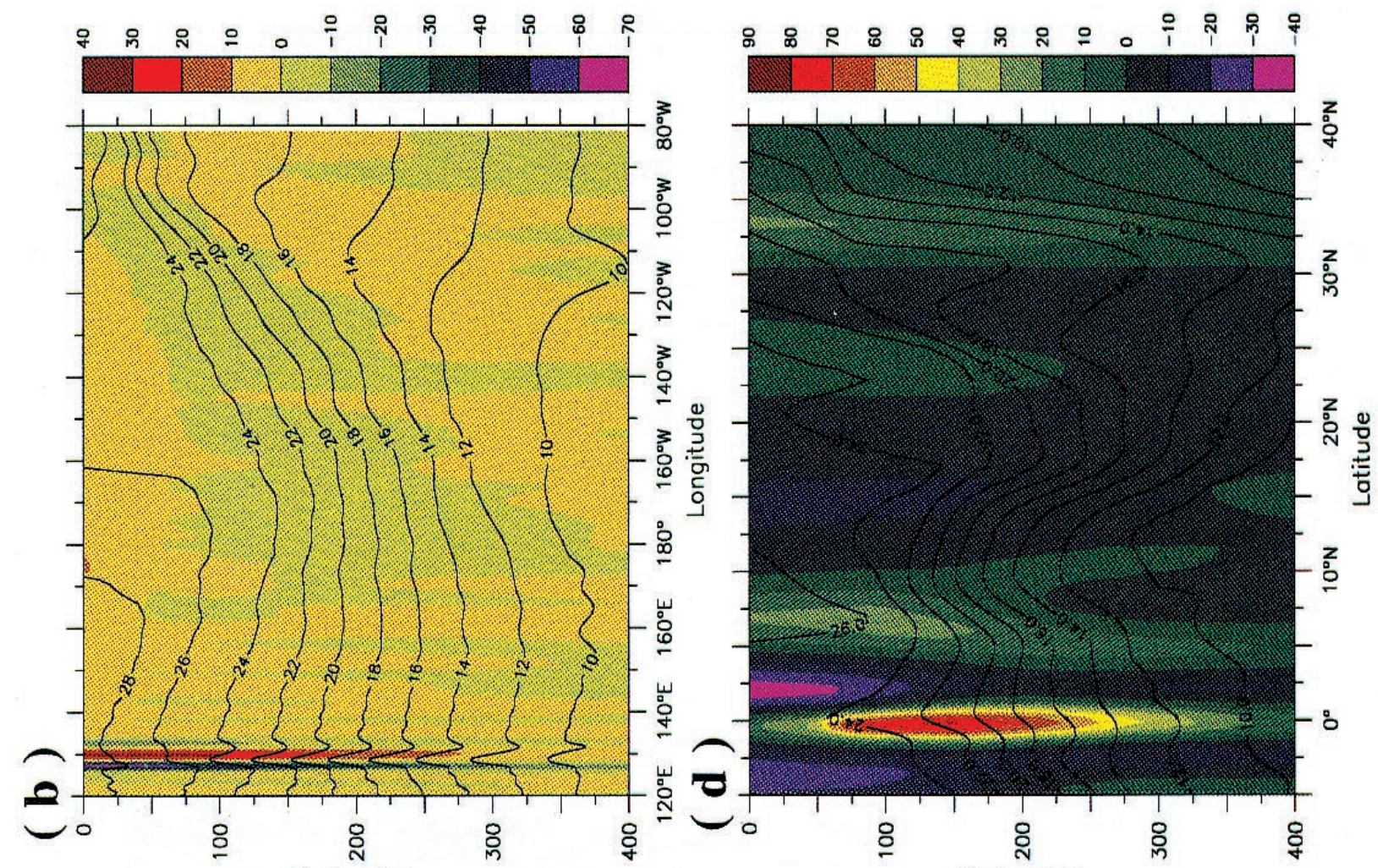

(iv) $47 d 20$

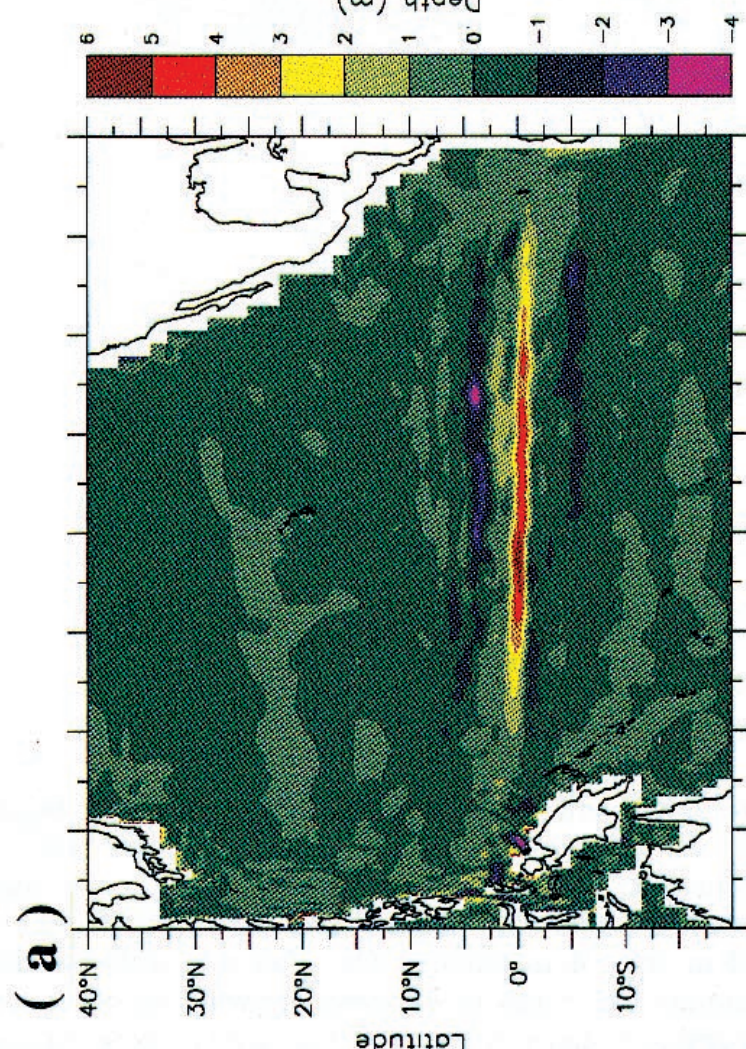

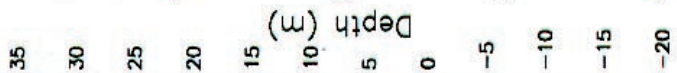

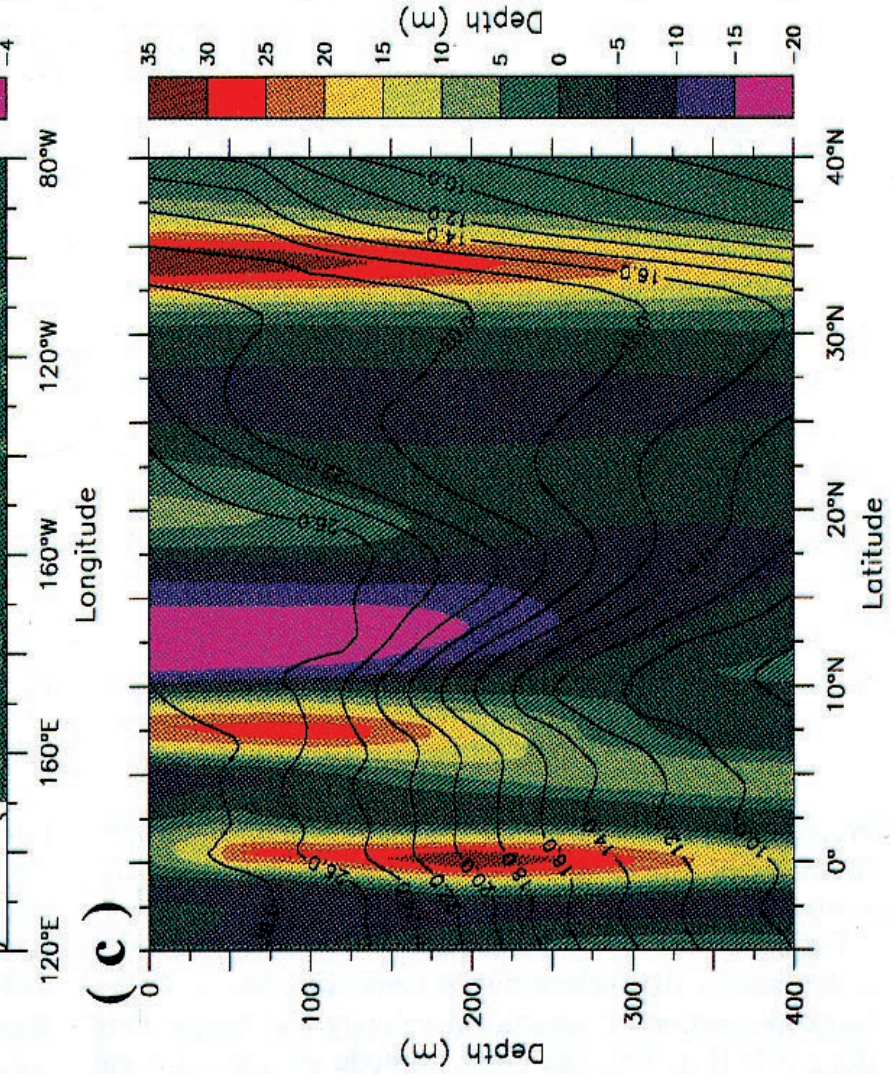




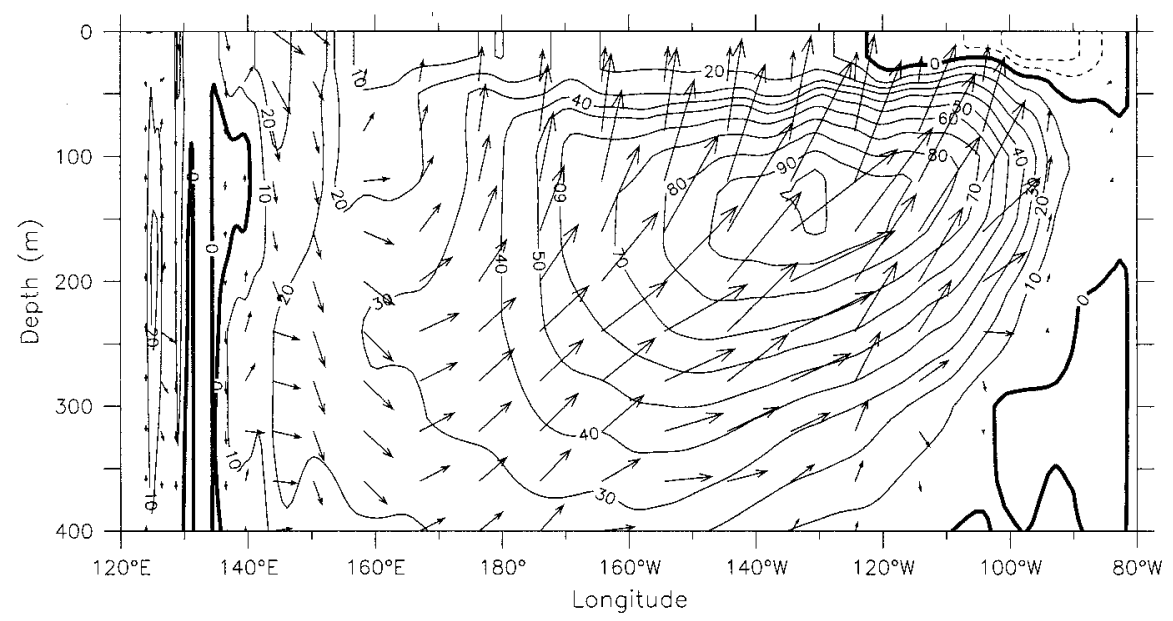

FIG. 7. Zonal current along the equator with $(u, w)$ velocity vectors superimposed. The contour intervals are $10 \mathrm{~cm} \mathrm{~s}^{-1}$ with the westward flow dashed.

Creary and Lu 1994, and discussed later in this section). In low-latitude regions between $5^{\circ}$ and $10^{\circ} \mathrm{N}$, the meridional flows are predominantly confined to the western boundary region via the LLWBC (Fig. 6b). Its magnitude is in sharp contrast to that in the ocean interior.

Below the mixed layer, the dominant features are the EUC, which flows across the entire equatorial Pacific (Fig. $3 b$; Figs. 6c-d) with a maximum speed of over $100 \mathrm{~cm}$ $\mathrm{s}^{-1}$ at $130^{\circ} \mathrm{W}$ and $100-\mathrm{m}$ depth, and the NECC with its core velocity in the lower mixed layer and upper thermocline. The complex tropical circulation is evident in the depth-latitude sections of zonal velocity and temperature for the western (Fig. 6c) and central (Fig. 6d) Pacific regions, characterized by a vigorous, meridionally banded zonal current structure and a trough-ridge structure in the temperature field. Figure 7 further illustrates the zonal structure of the EUC and the associated vertical circulation along the equator. The simulated zonal currents and temperature at $155^{\circ} \mathrm{W}$ are in agreement with the corresponding observations (Wyrtki and Kilonsky 1984).

Another notable feature appearing in the streamfunction contours (Fig. 2c) are two counterrotating gyres in the mixed layer of the central equatorial region separated by the EUC. These two gyres are confined to within $5^{\circ}$ of the equator with strong north-south asymmetry. The southern gyre has a transport of about $30 \mathrm{~Sv}$ (Sv $\equiv 10^{6} \mathrm{~m}^{3} \mathrm{~s}^{-1}$ ), about three times larger than the northern one, and is almost entirely confined to the mixed layer. However, in the thermocline (Fig. 2d), the stronger cyclonic gyre is located in the northeastern Tropics. These tropical gyres are important in defining the subtropical/ tropical pathways, as will be seen shortly.
These numerical solutions have some problems in detailed comparisons with the corresponding observations in the Tropics. These include a somewhat weak tropical thermocline, with slightly colder than observed sea surface temperature in the equatorial central and eastern Pacific and the lack of both a deeper, westward Equatorial Intermediate Current (EIC) beneath the EUC (Fig. 6d) and a New Guinea Coastal Undercurrent (NGCU; Fig. 3b). In the far western Pacific there is also eastward flow along the equator in the surface mixed layer associated with strong equatorial downwelling (Fig. 3a and Fig. 7), which are both not observed. We believe that the lack of a model EIC might be due to the model's reduced-gravity configuration; we simply do not properly resolve the physics of this deep current. The missing NGCU may be related to model grid configuration; the present grid does not properly distinguish the New Guinea and New Britain land mass. Another possible explanation for the lack of a model NGCU might have to do with the closed Indonesian Throughflow in this experiment. The surface eastward flow on the equator is probably due to a too-large vertical mixing there; this is a problem with most numerical simulations. Nevertheless, an overall comparison of these results with the available observations indicates that the model does well in capturing most of the important circulation features.

\section{c. The low-latitude western boundary currents}

As the NEC flows westward across the basin and encounters the Philippines, it splits into a northwestwardflowing current (the Kuroshio), and a southward-flowing

FIG. 6. The simulated horizontal distribution of vertical velocity in unit of meters per day (a); depth-longitude section of meridional velocity and temperature along $5^{\circ} \mathrm{N}(\mathrm{b})$; depth-latitude sections of zonal velocity and temperature along (c) $160^{\circ} \mathrm{E}$ and along $(\mathrm{d}) 155^{\circ} \mathrm{W}$, respectively. 
western boundary current. The later is the model representation of the Mindanao Current (MC: Fig. 6b), which is accompanied by a cyclonic circulation (the Mindanao eddy: Lukas et al. 1991). The model MC extends $100 \mathrm{~km}$ eastward offshore and to a depth of about $400 \mathrm{~m}$. A strong southward flow of more than 50 $\mathrm{cm} \mathrm{s}^{-1}$ is found to the west of the Mindanao eddy, with the maximum southward flow of $70-80 \mathrm{~cm} \mathrm{~s}^{-1}$ located at $6^{\circ} \mathrm{N}, 127^{\circ} \mathrm{E}$. This is accompanied by a northward return flow of about $5-10 \mathrm{~cm} \mathrm{~s}^{-1}$ as part of the eddy just to the east. This LLWBC, with a total southward transport of about $40 \mathrm{~Sv}$ (Fig. 1b), is important as it reconnects the interior circulation and helps to close the ocean circulation between the subtropics and Tropics. It is encouraging that the solutions in this model, with high longitudinal resolution near the western boundary (as well as other model characteristics) obtains a simulated Mindanao Current that is in good quantitative agreement with the observed currents (Lukas et al. 1991).

\section{d. Subtropical and equatorial cells}

Figure 8 presents the simulated velocity fields on four zonal sections from the subtropical gyre (Fig. 8a) to the equator (Fig. 8d), which clearly indicate the existence of meridional circulations such as a subtropical cell (STC) and equatorial cells (McCreary and Lu 1994). The model STC consists of subtropical subduction in the north (Fig. 8a), equatorward flow in the thermocline, upwelling at the equator (Fig. 8d), and then poleward flow in the surface mixed layer back toward midlatitude. However, the vertical flow pattern varies considerably with longitude, suggesting that the STC is not a basinwide feature. For example, along $25^{\circ} \mathrm{N}$ (Fig. 8a) there is upwelling over a large longitudinal span in the central Pacific region, sandwiched between the expected Ekman-induced downwelling. On the equator (Fig. 8d), there is a broad upwelling region in the central and eastern Pacific, accompanied by a downwelling band in the far western region (also in Fig. 7).

Embedded within this large-scale STC is the familiar equatorial meridional/vertical circulation cell in the eastern half of the basin, which can be seen in the upper layer above the main thermocline (Fig. 9). This equatorial cell consists of upwelling on the equator, divergence in the surface layer, relatively broad downwelling off the equator (the maximum is located at about $3^{\circ}-$ $4^{\circ} \mathrm{N}$ in the NECC region), and a subsurface, convergent equatorward flow (Fig. 6a and Fig. 8). Its meridional extent coincides with that of the two equatorial gyres in the central Pacific Ocean (Fig. 1b). This equatorial cell also contains significant zonal variability linked directly with the zonal variability of the model EUC (Fig. 7). Thus, this local equatorial cell is fundamentally a three-dimensional circulation cell and is also not a basinwide phenomenon.

There are marked differences in the vertical structure of the velocity fields between the western boundary and interior. The baroclinic structure of meridional flow is evident in the interior, with poleward flows in the surface mixed layer but equatorward flow in the thermocline (the right panels in Fig. 8). In the western boundary region, however, there is a strong equatorward flow characterized mainly by a depth-independent structure (the left panel in Fig. 8). Also, the meridional flows vary remarkably from the broad, Sverdrupian interior ocean to the western boundary. The ratio of meridional velocity in the boundary to the interior is at least 10:1. Thus, the LLWBC is the main pathway by which subtropical thermocline water flows into the Tropics.

Although it is relatively weaker and confined to very limited regions in both longitude and depth, we do find a significant subsurface equatorward flow of subtropical water in the ocean interior. This can be clearly seen in Fig. 8b for the depth-longitude section of meridional velocity along $10^{\circ} \mathrm{N}$ where the subtropics and Tropics border each other. This is further demonstrated in Fig. 10, which shows a depth-latitude section of meridional velocity along $150^{\circ} \mathrm{E}$. Thus, subtropical waters in this model experiment are indeed able to flow directly into the Tropics through the ocean interior.

\section{e. Mean water pathways: Summary of the three-dimensional circulation}

Based upon the preceding description, the model's mean water pathways can be summarized as either recirculation flows within the major gyres or cells or exchange flows between subtropical and tropical gyres and cells. Figure 11 schematically summarizes the mean water pathways.

One common pathway is a recirculation around the gyres and cells. For example, waters circulate within the North Pacific subtropical gyre and in the Mindanao eddy in the tropical western Pacific. Subsurface, we find a mean tropical northeastern gyre, which plays an important role in helping define the interior exchange flows. The various meridional and zonal sections also suggest that there are local recirculation flows within the Tropics. For example, the familiar equatorial cell provides a path for water to flow locally above the thermocline: upwelling to the sea surface on the equator, off-equatorial divergence at the sea surface, downwelling at $3^{\circ}-4^{\circ} \mathrm{N}$ due to Ekman convergence, and an equatorward return flow at depth.

There are also exchange flows of water across both model gyres and cell boundaries. The important direct water exchange between the subtropics and Tropics is accomplished by the STC, which consists of both surface and subsurface branches; water can flow from the subtropics to the Tropics in the thermocline and return to the subtropics in the surface mixed layer. However, the exact exchange flows are complicated by the wellorganized thermocline structure, the LLWBC, and the tropical current system. Table 1 gives the estimated 


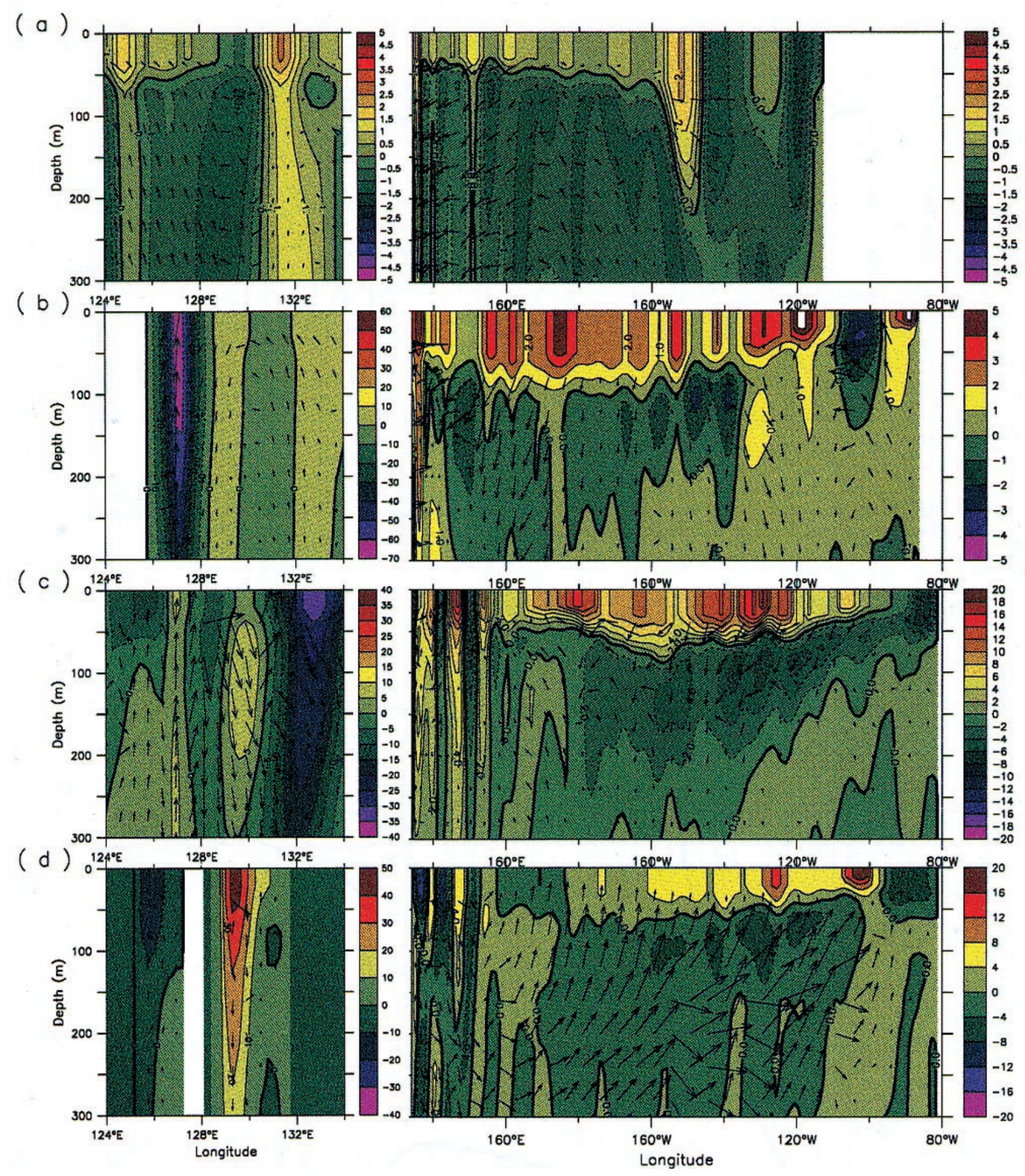

FIG. 8. Depth-longitude section of meridional velocity, with the $(u, w)$ velocity vectors superimposed, along (a) $25^{\circ}$, (b) $10^{\circ}$, (c) $3^{\circ}$, and (d) $0.2^{\circ} \mathrm{N}$, respectively. Contours are meridional velocity, arrows are zonal and vertical velocities. Note that the zonal scales have been stretched in the western boundary regions (the four left panels) relative to the east (the four right panels); different scales of color contour and velocity vectors are used in these eight panels; $\sim 0.4$-inch vectors of the velocity arrow plots on $u$ and $w$ indicate velocity magnitudes of 30 in the four left panels, and of 20,10,60, and 70 in the four right panels, respectively. 


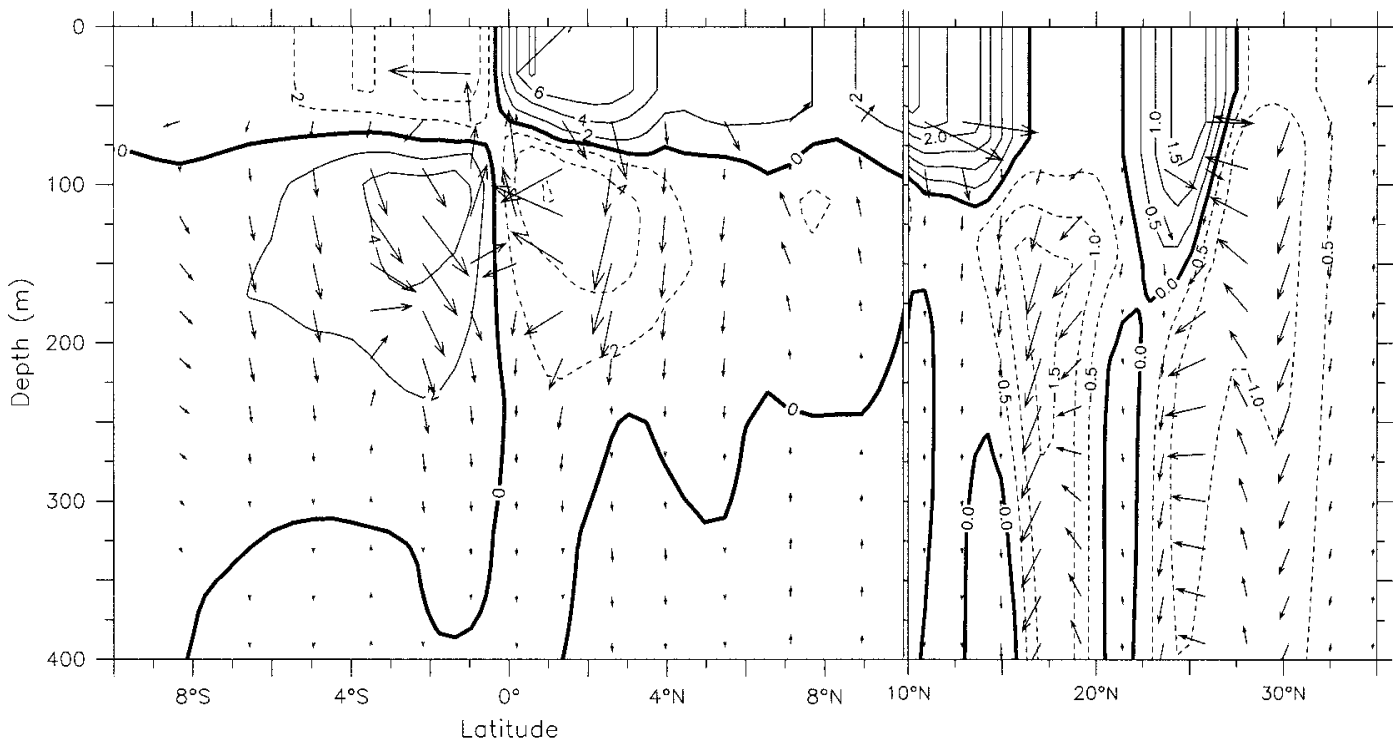

FIG. 9. Depth-latitude sections of meridional velocity along $155^{\circ} \mathrm{W}$, with the $(v$, w) velocity vectors superimposed. The contour intervals are $1 \mathrm{~cm} \mathrm{~s}^{-1}$ with the southward flow dashed. Note the stretched plotting in latitude for the tropical Pacific regions and different vector scales used in the figure.

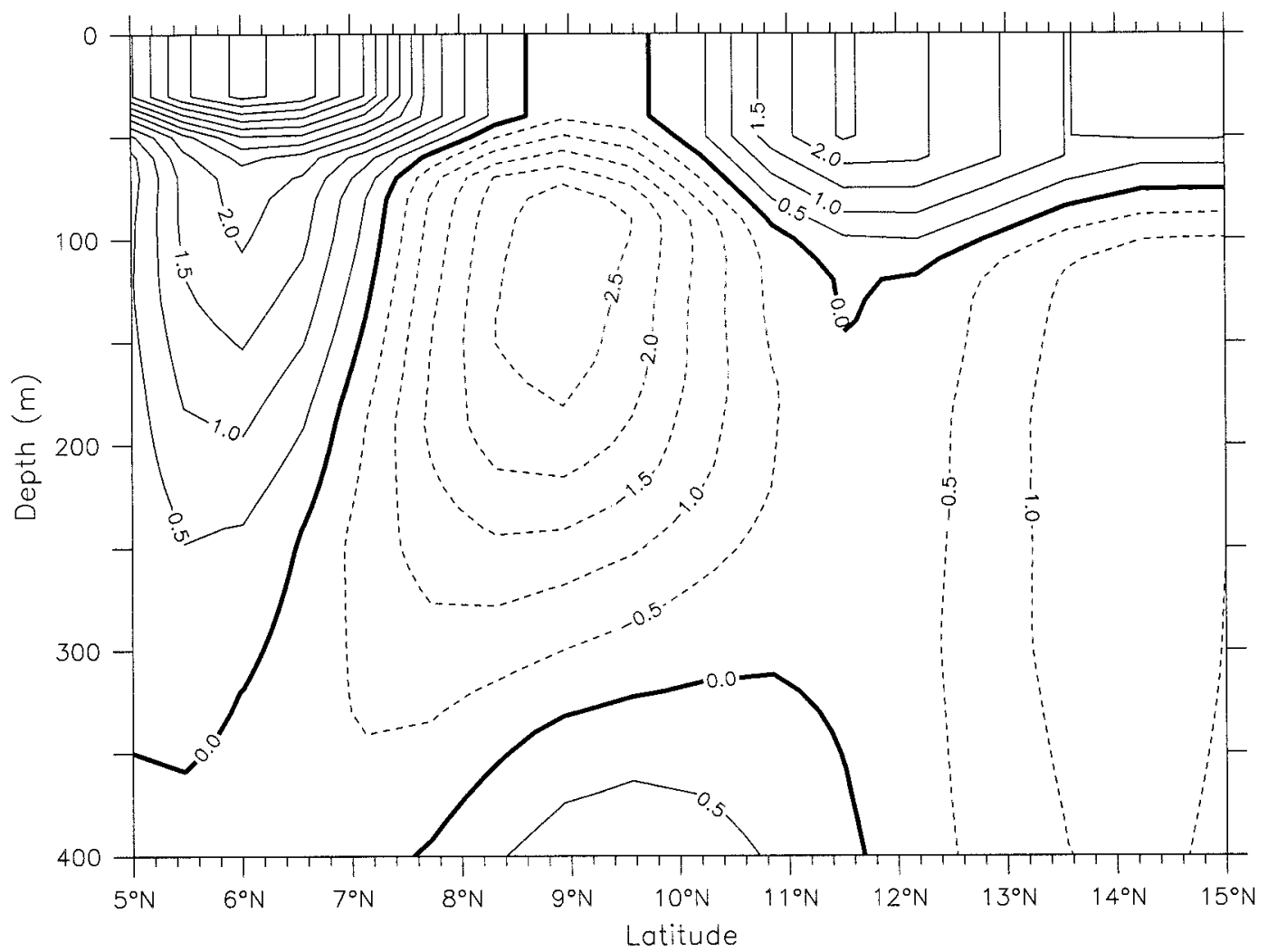

FIG. 10. Depth-latitude sections of meridional velocity along $150^{\circ} \mathrm{E}$. The contour intervals are $0.5 \mathrm{~cm} \mathrm{~s}^{-1}$ with the southward flow dashed. 


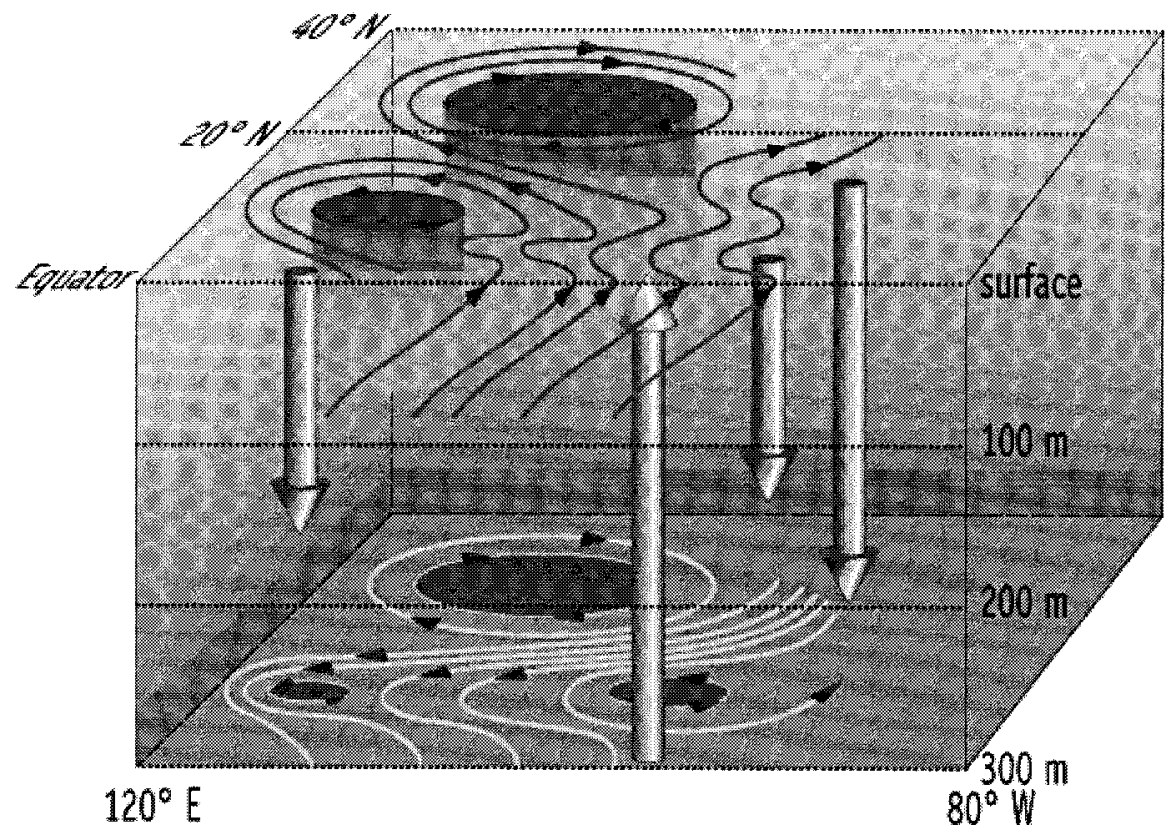

FIG. 11. A schematic diagram illustrating the water pathways in the North Pacific subtropical/ tropical upper ocean, as well as the main horizontal gyres and meridional-vertical cells of the ocean circulation. The shading regions with thin arrows indicate horizontal gyres: the subtropical gyre and the Mindanao eddy in the surface layer, and the additional tropical northeastern gyre at depth. The big arrows indicate vertical motions: the equatorial upwelling in the central and eastern Pacific, downwelling in the far western equatorial Pacific and in the off-equatorial North Pacific along $3^{\circ}-$ $4^{\circ} \mathrm{N}$, and the subduction in the broad subtropics.

transport of exchange flows from the subtropics into the Tropics, separately for the surface mixed layer and the underlying subsurface layers.

\section{1) MiXed-LAYER WATER PATHWAYS FROM THE TROPICS TO THE SUBTROPICS}

The flow patterns in the surface mixed layer are shaped by a large-scale, surface Ekman drift. Upwelled water on the equator first extends westward in the SEC, moves off the equator (via the Ekman drift) to find the eastward NECC, and then continues to move off the equator (avoiding the tropical downwelling just off the equator and therefore the mixed-layer tropical cell) to again flow westward in the NEC to reach the western Pacific, either to join the subtropical gyre recirculation or the LLWBC region that returns this water to the Tropics (about $4 \mathrm{~Sv}$ ). There is also a water pathway from the equatorial region into the subtropics directly through the ocean interior; after leaving the NEC, some water flows directly northeastward with the Subtropical Countercurrent to feed the subducted thermocline water in the northeastern subtropical Pacific.

\section{2) THERMOCLINE WATER PATHWAYS FROM THE SUBTROPICS TO THE TROPICS}

These flow patterns mainly reflect geostrophic circulation in the thermocline. Subtropical North Pacific water does not flow directly to the equator in the eastern and central Pacific. Instead, water first flows almost zonally westward across the basin in the NEC region. Most of the subtropical water that reaches the equator flows southward through the deeper LLWBC; we find approximately $34 \mathrm{~Sv}$ of water moving equatorward through the LLWBC below the mixed layer. Some water exits the boundary current and turns eastward to continue its journey in the deeper region of the NECC (16 $\mathrm{Sv}$ at $140^{\circ} \mathrm{E}$ ) and finally penetrates toward the equator in a zigzag pattern; some water flows southward directly along the western boundary to arrive on the equator, providing the initial transport of the EUC (about $32 \mathrm{~Sv}$ at $153^{\circ} \mathrm{E}$, in reasonable agreement with observed estimates of about $25 \mathrm{~Sv}$ of subtropical water; Butt and Lindstrom 1994). The LLWBC serves as the main southward conduit for water from the subtropics.

In addition to these LLWBC pathways, there is a direct flow from the subtropical North Pacific to the equator through a relatively narrow longitudinal (i.e., north-south) conduit in the western tropical Pacific across $10^{\circ} \mathrm{N}$ (Fig. 10), totaling approximately $3 \mathrm{~Sv}$ (estimated in the region between $140^{\circ}$ and $160^{\circ} \mathrm{E}$ ). This water joins water from the LLWBC region to total approximately $17 \mathrm{~Sv}$ that is swept eastward by the deeper regions of the NECC, finally penetrating toward the equator in the central and eastern Pacific and increasing the EUC transport in the central and eastern equatorial 
TABLE 1. Water transport (Sv) in the surface mixed layer and the underlying subsurface layers. Velocity and layer thickness are integrated at given latitude or longitude of interest to estimate the exchange flows from the subtropics to the Tropics.

\begin{tabular}{|c|c|c|c|c|c|}
\hline & $\begin{array}{l}\mathrm{MC} \text { at } 10^{\circ} \mathrm{N} \\
125^{\circ}-130^{\circ} \mathrm{E}\end{array}$ & $\begin{array}{c}\text { Ocean interiors } \\
\text { at } 10^{\circ} \mathrm{N} \\
140^{\circ}-160^{\circ} \mathrm{E}\end{array}$ & $\begin{array}{c}\mathrm{NECC} \text { at } 140^{\circ} \mathrm{E} \\
6^{\circ}-10^{\circ} \mathrm{N}\end{array}$ & $\begin{array}{c}\mathrm{EUC} \text { at } 153^{\circ} \mathrm{E} \\
3^{\circ} \mathrm{S}-3^{\circ} \mathrm{N}\end{array}$ & $\begin{array}{c}\mathrm{EUC} \text { at } 145^{\circ} \mathrm{W} \\
3^{\circ} \mathrm{S}-3^{\circ} \mathrm{N}\end{array}$ \\
\hline $\begin{array}{l}\text { Mixed layer } \\
\text { Subsurface layers }\end{array}$ & $\begin{array}{r}4.4 \\
33.9\end{array}$ & $\begin{array}{l}0.0 \\
2.9\end{array}$ & $\begin{array}{r}1.0 \\
15.9\end{array}$ & $\begin{array}{r}2.6 \\
31.8\end{array}$ & $\begin{array}{r}1.0 \\
47.3\end{array}$ \\
\hline Total & 38.3 & 2.9 & 16.9 & 34.4 & 48.3 \\
\hline
\end{tabular}

Pacific (about $47 \mathrm{~Sv}$ at $145^{\circ} \mathrm{W}$ ). This direct interior ocean pathway is also suggested by McPhaden and Fine (1988), but was missing from the model simulations of Lu and McCreary (1995). Our estimate of 3 Sv appears to be consistent with estimates from tracer observations (J. P. McCreary and R. A. Fine 1996, personal communication).

Finally, some subtropical water never does quite make it all the way to the equator. Water recirculates in and below the thermocline in a cyclonic gyre in the northeastern Tropics (Fig. 2d). In the terminology of ventilated thermocline theory (Luyten et al. 1983), the easternmost arm of subducted subtropical water that does make it to the Tropics defines the westward boundary of a "shadow zone" (i.e., no-flow region) to the east where, in fact, we do find flow, that is, the recirculating gyre. Working to break the theoretical no-flow constraint within this region, water from directly on the equator (where the theory is not valid) fills the region via the EUC. Flow within this region is also possible due to the strong diabatic processes of the eastern tropical region of the model. These diabatic processes must play an important role for the existence of this recirculating cell.

\section{Isopycnal analyses}

We now endeavor to place these results within a more dynamical framework and find it useful to revisit the preceding description within that context. As seen in Figs. 4 and 5, the depth of an isopycnal surface varies considerably in both longitude and latitude. Isopycnal surfaces, which are at great depth in the middle of the subtropical gyre, rise with increasing latitude to eventually intersect the sea surface (outcropping). Water moves freely down these sloping isopycnal surfaces, thus providing direct pathways from the surface mixed layer to the thermocline. Furthermore, the sloping of isopycnal surfaces with depth is not uniform either in the horizontal or the vertical. The earth's rotation further constrains fluid motion along particular circuits (geostrophic contours) on isopycnals. In order to better understand the dynamical basis for the model's water pathways, we have evaluated a number of fundamental quantities on different isopycnal surfaces.

\section{a. Definition of the isopycnal fields}

Since the model uses $\sigma$ as the vertical coordinate, we define the actual depth at the center of a $\sigma$ layer where model variables are available. Then the value at a given depth is interpolated vertically. The quantities selected for this analyses include the Bernoulli function $B$, velocity fields, potential vorticity $Q$, and mass transport streamfunction $\psi$. Here $B$ is defined as (Cox and Bryan 1984)

$$
B(\sigma)=\rho_{0} g \eta+g \int_{z(\sigma)}^{0}[\rho-\rho(\sigma)] d Z,
$$

where $\sigma=\rho-1000$ is the isopycnal surface of interest and $\eta$ is the sea surface elevation (Fig. 3a). As defined, $B$ are geostrophic streamlines that measure geostrophic flows away from the equator. Potential vorticity $Q$ not only reflects the thermocline structure but also gives an indication of water pathways in that $Q$ is approximately conserved along streamlines below the mixed layer. The mass transport streamfunction $\psi$ at a specific isopycnal surface $\sigma$, integrated between specified isopycnal surfaces $\Delta \sigma$, represents a quantitative estimate of water mass flow and is defined as

$$
\begin{aligned}
& \psi_{x}=h_{\Delta \sigma} v_{\sigma} \\
& \psi_{y}=-h_{\Delta \sigma} u_{\sigma},
\end{aligned}
$$

where $h_{\Delta \sigma}$ is layer thickness between $\sigma-\Delta \sigma$ and $\sigma+$ $\Delta \sigma$. Since there are large basinwide subduction and upwelling/downwelling velocities, that is, significant convergent and divergent flows on an isopycnal surface, the steamfunction as calculated from the horizontal velocity fields can be somewhat different from the actual flow patterns. Comparisons between the current fields and $B, \psi$ indicate that the orientation of $B$ contours consistently coincide with the currents at model grid points, but $\psi$ contours do not, in some areas, such as in the subtropical western boundary where horizontal flows have a large convergent component. This suggests that $B$ contours can provide precise water pathways throughout most of the domain.

\section{b. Water pathways}

Figure 12 shows horizontal maps of the depth of the $\sigma=24.0$ isopycnal surface and the Bernoulli function 


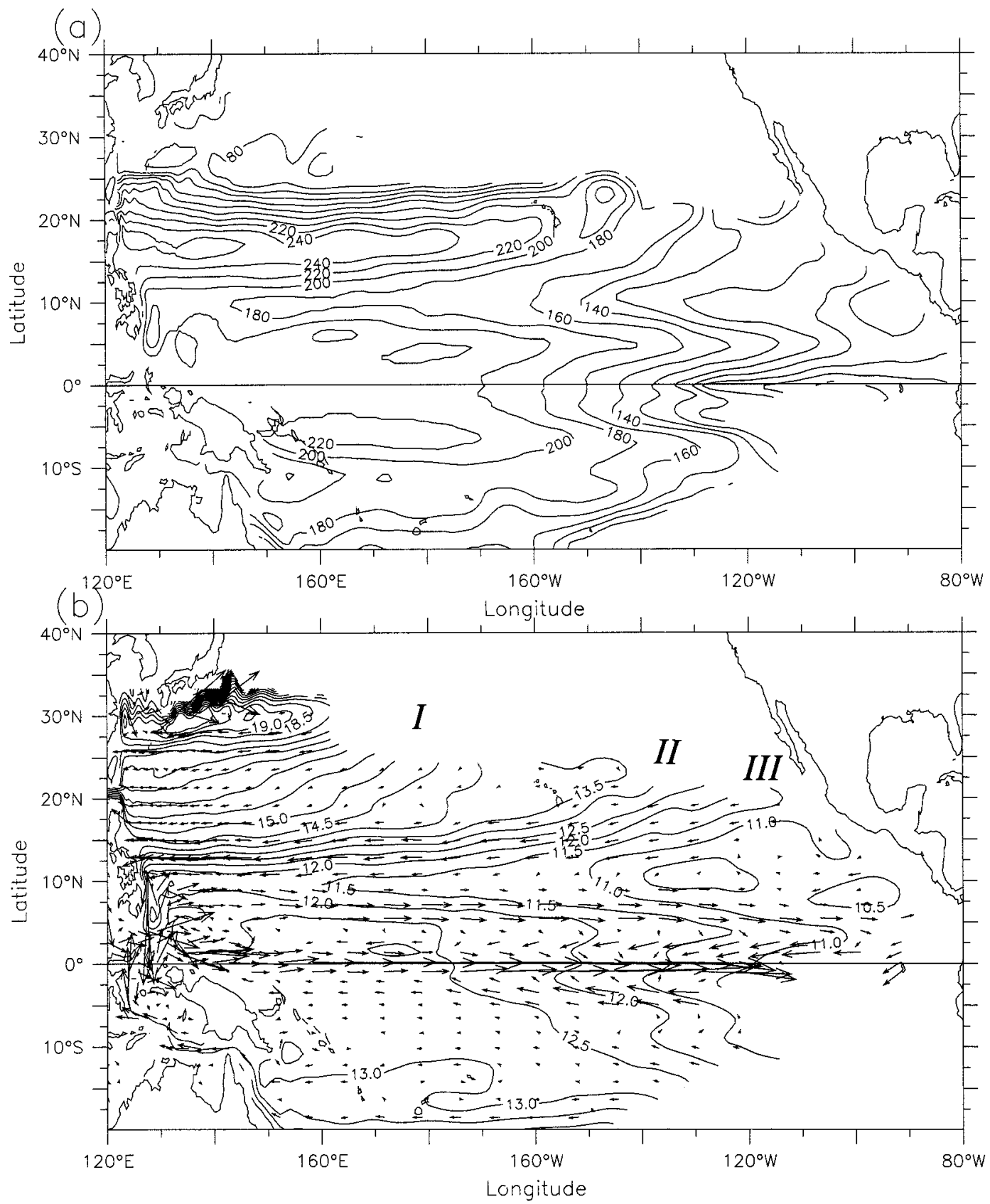

FIG. 12. Quantities evaluated on the $\sigma=24.0$ isopycnal surface for depth of the surface (a); Bernoulli function and $(u, v)$ current vectors (b). The contour intervals are $20 \mathrm{~m}$ in (a) and $0.5 \mathrm{~cm}$ in (b).

on that surface. This surface is within the ventilated thermocline. Its depth exceeds the mixed layer depth over much of the subtropical gyre, with a clear zonally oriented trough-ridge structure (also see Fig. 5). The maximum depth lies at latitudes between $15^{\circ}$ and $20^{\circ} \mathrm{N}$ in the western and central Pacific Ocean, with strong gradients to the north. A tropical trough is seen to extend from the eastern boundary across the entire basin along $10^{\circ} \mathrm{N}$.

Mean water pathways can be seen in the velocity vectors and the $B$ contours (Fig. 12b). Flow patterns can be separated into regions with blocked (by mixed layer outcropping or by land boundaries) and closed $B$ contours. Recirculating flows occur within closed $B$ contours, such as in the far northwestern part of the subtropical gyre and the tropical northeastern Pacific. In contrast, subtropical/tropical exchange flows occur along blocked $B$ contours, which thread up to the sea surface toward the outcrop regions. Such water advection is evident, originating at the outcrop boundary in the northeastern subtropical gyre. 
Basically, there are three different pathways that find origins from the subduction process. The first pathway subducts water in the western and central part of the northern subtropical gyre (west of $170^{\circ} \mathrm{W}$, denoted as $\boldsymbol{I}$ in Fig. 12b) and extends westward, returning northward after intersecting the western boundary to recirculate within the gyre. The subducted region for the second pathway is farther to the east and south of the subtropical gyre (between $170^{\circ}$ and $120^{\circ} \mathrm{W}$, denoted as $\boldsymbol{I I}$ in Fig. $12 \mathrm{~b})$. After subduction, water parcels move westward and southward into the low-latitude western boundary regions where they turn equatorward in two ways. One is that, after leaving the LLWBC, water turns eastward within the lower regions of the NECC to approach the equator in rather a zigzag pattern. Some of this water enters the Tropics in the interior of the basin. The other is a pathway that directly approaches the equator along the western boundary without entering the NECC. The third main subduction pathway originates in the subtropics near the coast of North America (east of $120^{\circ} \mathrm{W}$, denoted as $\boldsymbol{I I I}$ in Fig. 12b) and penetrates toward the equator without ever entering the LLWBC region; water parcels first move westward in the NEC and then turn southward in the ocean interior of the western Pacific to help define the eastward flowing NECC, and then finally zigzag to join the EUC in the central and eastern Pacific regions. However, most streamlines in this simulation reach the equator through the LLWBC where they are then swept eastward by the NECC. The eastward flowing NECC causes some water parcels to run directly to the east all the way across the basin, unable to reach the equator. These results are qualitatively consistent with previous theoretical (Pedlosky 1991b) and idealized numerical (McCreary and Lu 1994) results where a critical streamline is found that divides the active subtropical gyre from an eastern "shadow zone." Given the attempt at realistic simulations in our study, one simple dividing streamline cannot be easily identified.

Figure 13 shows horizontal maps of the depth of the $\sigma=24.6$ isopycnal surface, the Bernoulli function with current vectors, $Q$, and the mass transport streamfunction, respectively. This isopycnal surface is also within the ventilated thermocline (also see Fig. 5), with its maximum depth just to the south of the Kuroshio near Japan. A ridge is located to the south of the subtropical gyre at latitudes between $15^{\circ}$ and $20^{\circ} \mathrm{N}$ in the western and central Pacific Ocean, extending northeastward toward the outcropping regions. To the south, there is a tropical trough that extends westward from the eastern boundary. Similar flow patterns as on the $\sigma=24.0$ surface are present. For example, this surface also has three types of geostrophic streamlines, but here more streamlines from the subtropical gyre are likely to penetrate to the equator through the western boundary (Fig. $13 \mathrm{~b})$. Furthermore, a clearer signature of the ventilated thermocline is illustrated by the open $Q$ contours (Fig. 13c). In the northeastern part of the gyre, where we find large $Q$ gradients, both low and high $Q$ bands extend westward from the outcrop regions. In the northwestern portion of the subtropical gyre, there is a pronounced minimum homogenous $Q$ region that covers great spans in both the vertical (Figs. 4 and 5) and the horizontal, bounded by sharp $Q$ gradients to the north and to the southeast. Farther to the east and south, there is a low $Q$ region near the California coast that extends a bit to the southwest, bounded by a maximum region of closed $Q$ contours in the northeastern Tropics (centered around $12^{\circ} \mathrm{N}, 140^{\circ} \mathrm{W}$ ). A similar basin-scale $Q$ structure has been observed by Talley (1988) and many others.

The streamfunction map (Fig. 13d) shows the dominant subtropical gyre in the North Pacific with a mean amplitude of $4 \mathrm{~Sv}$ between the 24.5 and 24.7 isopycnal surfaces. Also evident are the tropical western Pacific gyre (about $1.5 \mathrm{~Sv}$ between these density surfaces) and the two counterrotating equatorial gyres, asymmetrical about the equator, which have amplitudes of about 2.5 Sv.

Deeper within the unventilated thermocline (e.g., on the $\sigma=26.0$ and $\sigma=27.0$ isopycnal surfaces; not shown), the gyre circulation shrinks toward the northwest, consistent with the theoretical prediction of Rhines and Young (1982). The magnitude of water flow is significantly reduced from the surfaces above; the motion in the eastern tropical Pacific is especially very weak. There are actually no subtropical/tropical exchange streamlines through the ocean interior at these depths. Instead, water flows from the subtropics to the equator confined predominantly to the low-latitude western boundary region.

\section{c. Basinwide trajectories}

We next provide the corresponding kinematic picture of water particle behavior by calculating flow trajectories from these simulated mean velocity fields. Trajectories have been plotted over a 2 -yr period in Fig. 14 for the mixed layer and the $\sigma=24.6$ isopycnal surface. After two years, water particles have made long journeys that allow us to trace their pathways. The arrows in the figures indicate the terminus of the trajectories. Note that a limitation of this simple calculation is that these are not real trajectories; we simply temporally integrate the mean velocity field on isopycnal surfaces. Thus, there are at least three ways in which these pseudotrajectories might differ from true ones: large (enough) vertical velocity or exchange, significant mixing, and time dependence. All these processes are important to various regions. However, we find merit in showing these pseudotrajectories to augment our previous discussions of flow patterns in the model.

The trajectories in the surface mixed layer (Fig. 14a) have the clear signature of the wind-driven Ekman flow: poleward transport in both hemispheres. The trajectories on the $\sigma=24.6$ isopycnal surface (Fig. 14b) are dom- 

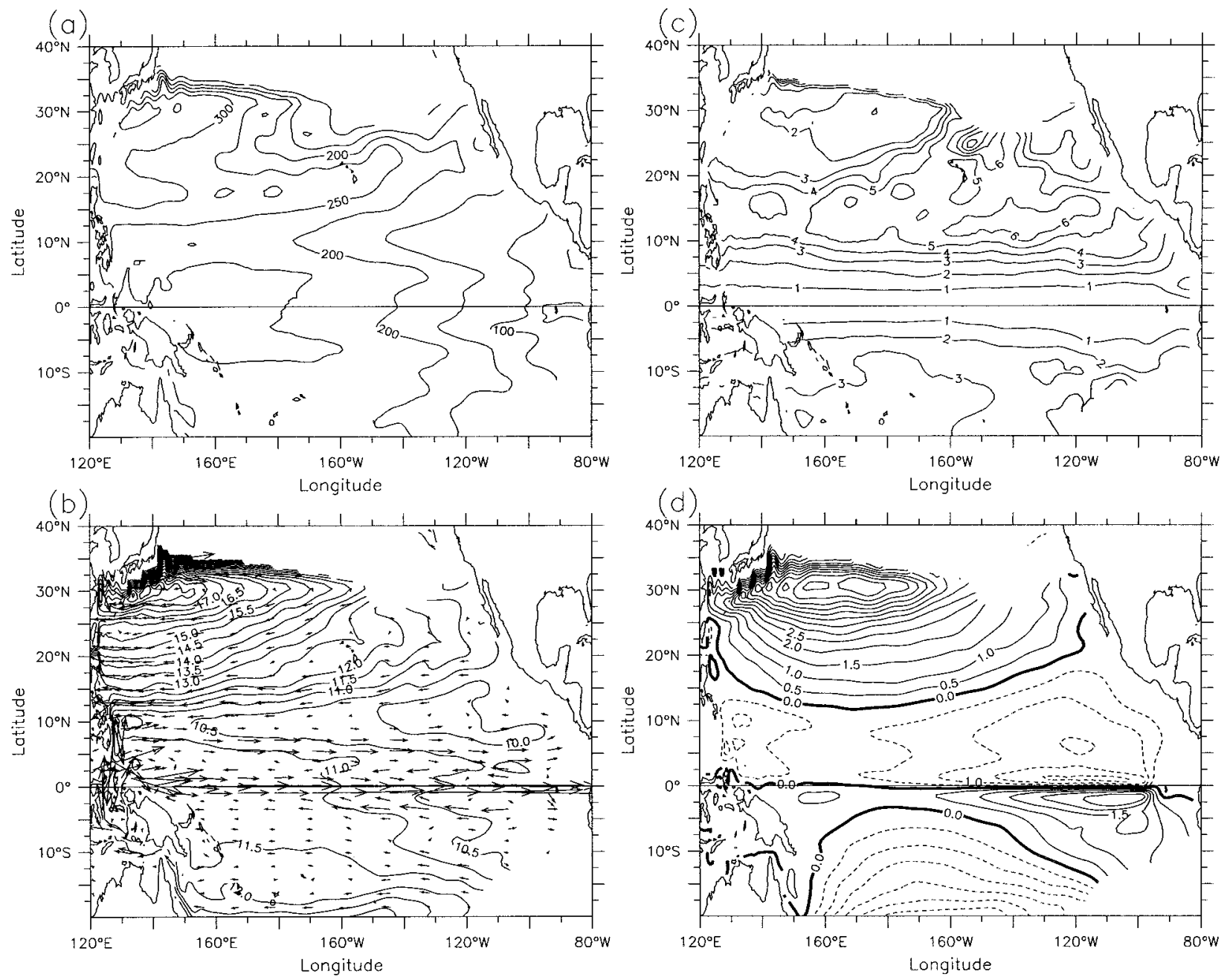

FIG. 13. Quantities evaluated on the $\sigma=24.6$ isopycnal surface: depth of the surface (a); Bernoulli function and ( $u$, $v$ ) current vectors (b); potential vorticity (c); and mass transport streamfunction integrated between the 24.5 and 24.7 isopycnal surfaces (d). The contour intervals are $50 \mathrm{~m}$ in (a), $0.5 \mathrm{~cm}$ in (b), $1 \times 10^{-10} \mathrm{~m}^{-1} \mathrm{~s}^{-1}$ in (c), and $0.5 \mathrm{~Sv}$ in (d).

inated by geostrophic flow, characterized by southward and westward movement north of $10^{\circ} \mathrm{N}$. These trajectories are consistent with the previous description of the regional and basinwide circulations. In particular, the horizontal structure of the STC is clearly depicted, as are the tropical recirculation gyres.

\section{d. Dynamics}

In addition to its quasi-conservative tracerlike nature, $Q$ is dynamically linked to the structure of the thermocline and, hence, the circulation. The $Q$ fields, therefore, act as dynamical maps for describing and explaining the water pathways in the North Pacific Ocean. For a layered ocean, the large-scale $Q$ is approximately proportional to $f / d h$, where $d h$ is the layer thickness between neighboring isopycnal surfaces. In the present model, all diabatic processes are contained within the mixed layer and the next lower layer; the layers below this are adiabatic. Therefore, regions of the model below the mixed layer will attempt to conserve $Q$.

Figure 15 shows the horizontal distribution of Bernoulli function evaluated on the $\sigma=25.0$ isopycnal surface (contours) and the inverse of the layer thickness (essentially $Q$ ) between the $\sigma=24.6$ and $\sigma=$ 25.4 isopycnal surfaces multiplied by 100 (color). The precise water pathways are represented here by the $B$ field; these can be dynamically understood by applying $Q$ conservation. The layer thicknesses vary geographically in the North Pacific subtropical/tropical upper ocean, departing significantly from latitude circles. The layer thickness is greatest (about $200 \mathrm{~m}$ ) in the northern portion of the subtropical gyre south of the Kuroshio and Kuroshio Extension, revealing a homogenized region of potential vorticity. There is also a closed minimum region of layer thickness (about 20 $\mathrm{m})$ in the central and eastern Pacific along $10^{\circ} \mathrm{N}$ just south of the NEC. At these model depths, $Q$ is con- 

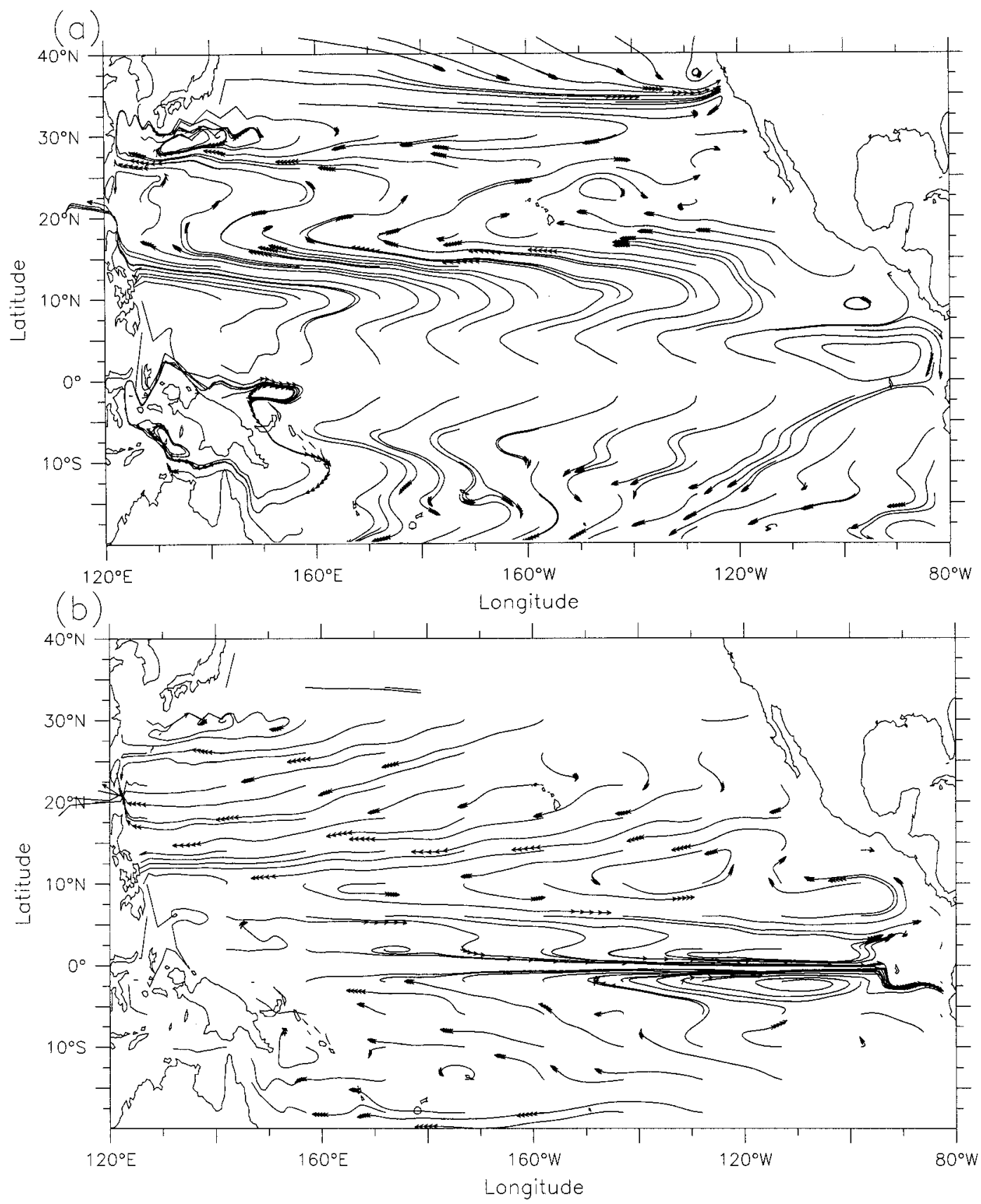

FIG. 14. Parcel trajectories, over a 2-yr period, using mean velocity fields for the mixed layer (a) and for the $\sigma=$ 24.6 isopycnal surface (b). The multiheaded trajectory vectors are plotted for clarity and also indicate particle speed in some way (i.e., sometimes the heads packed tightly and other times spead apart).

served along streamlines; that is, streamlines of the subsurface flow coincide with lines of constant $Q$. Thus, thermocline water must first move westward to the boundary to prevent from passing directly through this closed region of minimum thickness (or large $Q$ ) in the tropical central and eastern Pacific. Most waters then turn southward through the LLWBC. This largescale potential vorticity feature, essentially formed by the convergent winds of the intertropical convergence zone (Lu and McCreary 1995), is balanced by thermocline water that cannot move from the subtropical to the equatorial ocean. This homogenous " $\mathrm{Q}$ island" gives the rather vivid impression of flow "blockage" via a "potential vorticity barrier." More accurately, $Q$ is a dynamical tracer whose structure does not force the flow at all but is rather a signature of it.

Note that Fig. 15 more clearly shows a pathway described previously: water leaves the western boundary 


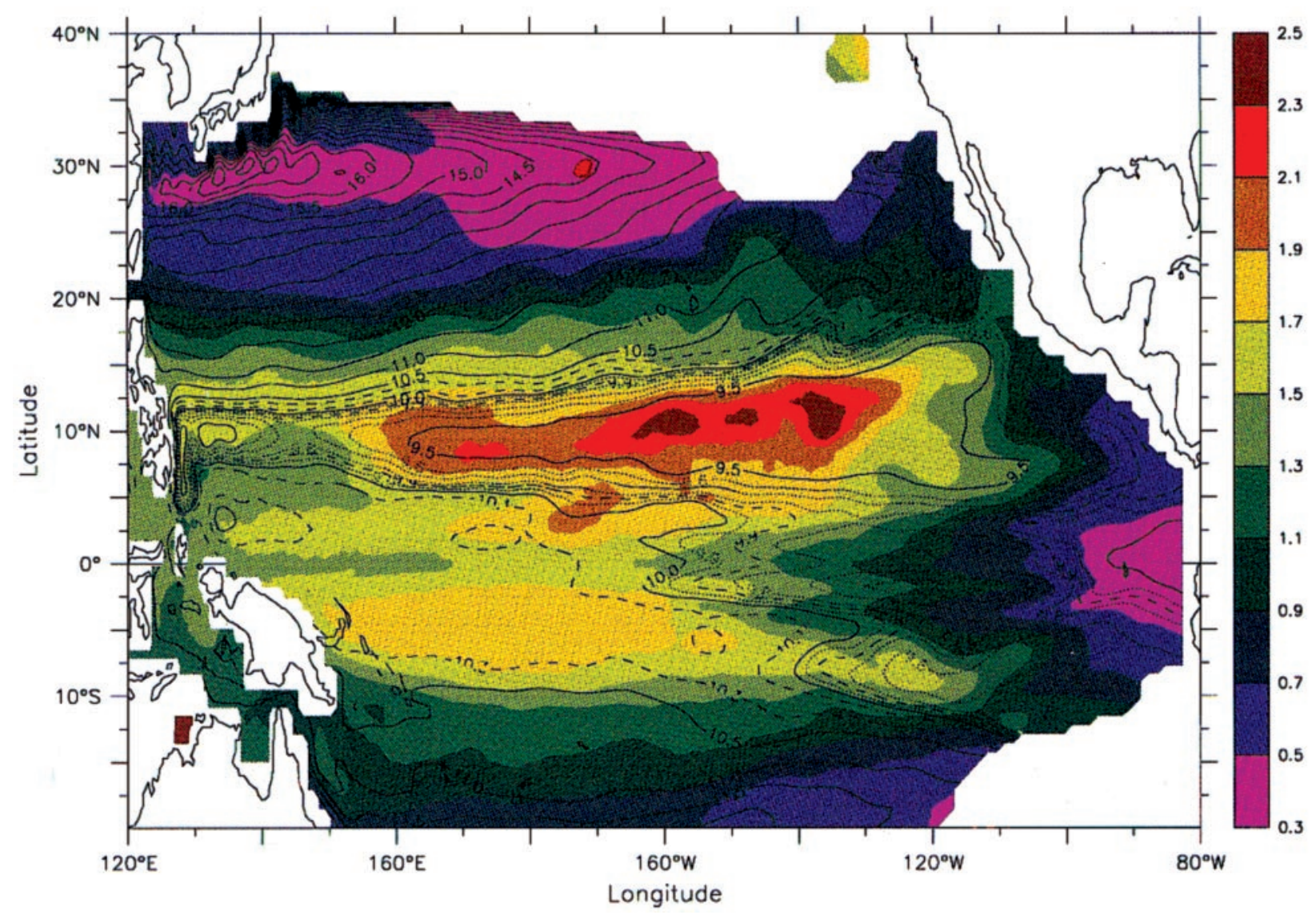

FIG. 15. Horizontal map showing the inverse of the layer thickness (essentially $Q$ ) between the $\sigma=24.6$ and the $\sigma=25.4$ isopycnal surfaces multiplied by 100 (color), with the Bernoulli function superimposed, evaluated on $\sigma=25.0$ isopycnal surface (contour).

current near $7.5^{\circ} \mathrm{N}$ as part of the model's deep NECC (also see Fig. 6c) and winds its way eastward and onto the equator near the date line. This pathway may also account for convergence of subtropical water in the central Pacific, although this flow does appear to be quite weak.

\section{Conclusions}

A reduced-gravity, primitive-equation ocean circulation model embedded with an explicit mixed layer submodel is used to study the mean water pathways between the North Pacific subtropical and tropical upper ocean. The circulation patterns in the mixed layer indicate that waters upwelling along the equator can avoid a local (meridional/vertical) tropical cell to supply the midlatitude subtropical regions. There are basically two pathways: One is through the midlatitude western boundary current (the Kuroshio) where these waters recirculate within the subtropical gyre. The other is directly through the STCC in the ocean interior, which is located in the northeastern part of the subtropical gyre. These pathways feed the midlatitude subduction sites where water is eventually swept southward at depth.
This thermocline water then crosses the basin, penetrating far from the northern subtropical gyre to feed the equatorial current system. But these thermocline waters only succeed in flowing toward the equator along very limited north-south paths in the tropical western Pacific. The LLWBC serves as the main southward circuit for these subducted thermocline waters. There is additionally an interior ocean route in the far western Pacific around $10^{\circ} \mathrm{N}$, involving long east-west excursions, that finally reaches the equator in the central and eastern Pacific Ocean.

We have described these mean water pathways from a number of vantage points. Besides the velocity fields and geostrophic streamlines (the Bernoulli function), which present the actual pathways, other quantities evaluated on isopycnal surfaces help to dynamically understand the circulation. In particular, it is well known that $Q$ not only provides a measure of the thermocline structure that basically controls the water pathways, but also reveals the ventilation mechanisms. The kinematic picture of the water pathways given by the flow trajectories complements the potential vorticity analysis.

The model water pathways are essentially consistent with our previous ideas, both observationally and from 
other modeling and theoretical studies. The picture emerging from these more realistic simulations is helpful in interpreting the tritium and other observations. In particular, our results for the thermocline water pathways are consistent with geostrophic flow patterns inferred from observations (Wyrtki 1975; McPhaden and Fine 1988), suggesting that there is a direct, interior flow of North Pacific subtropical thermocline water to the equator in the central and eastern Pacific regions. These results can also explain the equatorial tritium maximum in the central Pacific described by Fine (1987).

Significant low-frequency (interannual and interdecadal) climate variability has been identified and attributed to changes in large-scale ocean circulation. The strongest interannual variability is associated with El Niño over the tropical Pacific Ocean. Recent observations also show large decadal variability of upper-ocean thermal structure in the tropical and North Pacific (e.g., Zhang and Levitus 1996, 1997). These authors find coherent relationships between variations in the Tropics and midlatitudes, involving interactions on both interannual and decadal timescales over the entire Pacific basin. Thus, in addition to the mean water pathways described in this paper, there is a need to investigate the transient components of the system in order to understand both interannual and decadal variability and their interactions between the Tropics and subtropics.

Acknowledgments. We would like to thank Drs. Peter Gent and Mark Cane for providing the foundation of the upper-ocean circulation model, and to Drs. William Kessler, Julian McCreary, Zhengyu Liu, and RuiXin Huang for invaluable discussions. We wish to thank reviewers for their numerous comments and suggestions that helped to improve the original manuscript significantly. This research was supported by the National Oceanic and Atmospheric Administration through Grant NA 16RC022802, the TOGA Program on Seasonal to Interannual Prediction, and by the National Aeronautics and Space Administration through Grant RTOP 578-21-03.

\section{REFERENCES}

Bryden, H., and E. C. Brady, 1985: Dignostic model of the threedimensional circulation in the upper equatorial Pacific Ocean. $J$. Phys. Oceanogr., 15, 1255-1273.

Butt, J., and E. Lindstrom, 1994: Currents of east coast of New Ireland, Papua-New Guinea, and their relevance to regional undercurrents in the western equatorial Pacific Ocean. J. Geophys. Res., 99, 12503-12514.

Chen, D., L. M. Rothstein, and A. J. Busalacchi, 1994a: A hybrid vertical mixing scheme and its application to tropical ocean models. J. Phys. Oceanogr., 24, 2156-2179.

— A. J. Busalacchi, and L. M. Rothstein, 1994b: The role of vertical mixing, solar radiation, and wind stress in a model of simulation of the sea surface temperature seasonal cycle in the tropical Pacific Ocean. J. Geophys. Res., 99, $20345-$ 20359.

Cox, M. D., and K. Bryan, 1984: A numerical model of the ventilated thermocline. J. Phys. Oceanogr., 14, 674-687.

Cushman-Roisin, B., 1984: On the maintenance of the subtropical front and its associated countercurrent. J. Phys. Oceanogr., 14, $1179-1190$.

Fine, R. A., 1987: The penetration of tritium into the tropical Pacific. J. Phys. Oceanogr., 17, 553-564.

_ J. L. Reid, and H. G. Ostlund, 1981: Circulation of tritium in the Pacific Ocean. J. Phys. Oceanogr., 11, 3-14.

Firing, E., C. Fernander, and J. Miller, 1981: Profiling current meter measurements from the NOR-PAX Hawaii-to-Tahiti shuttle experiment. Data Rep. 39, HIG-81-2, Hawaii Institute of Geophysics, University of Hawaii, 146 pp. [Available from Institute of Geophysics, University of Hawaii, Honolulu, HI 96822.]

Gent, P. R., and M. A. Cane, 1989: A reduced gravity, primitive equation model of the upper equatorial ocean. J. Comput. Phys., 81, 444-480.

Hellerman, S., and M. Rosenstein, 1983: Normal monthly mean wind stress over the World Ocean with error estimates. J. Phys. Oceanogr., 13, 1093-1104.

Kraus, E. B., and J. S. Turner, 1967: A one-dimensional model of the seasonal thermocline, II, the general theory and its consequence. Tellus, 19, 98-106.

Levitus, S., 1982: Climatological Atlas of the World Ocean, NOAA Prof. Paper No. 13, U.S. Govt. Printing Office, 173 pp.

Liu, Z., 1994: A simple model of the mass exchange between the subtropical and tropical ocean. J. Phys. Oceanogr., 24, 11531165.

- S. G. H. Philander, and R. C. Pacanowski, 1994: A GCM study of the tropical-subtropical upper-ocean water exchange. J. Phys. Oceanogr., 24, 2606-2623.

Lu, P., and J. P. McCreary, 1995: Influence of the ITCZ on the flow of thermocline water from the subtropical to the equatorial Pacific Ocean. J. Phys. Oceanogr., 25, 3076-3088.

Lukas, R., E. Firing, P. Hacker, P. Richardson, C. Collins, R. Fine, and R. Gammon, 1991: Observations of the Mindanao Current during the western equatorial Pacific Ocean circulation study. $J$. Geophys. Res., 96, 7089-7140.

Luther, D. S., and E. Johnson, 1990: Eddy energetics in the upper equatorial Pacific during the Hawaii-to-Tahiti Shuttle Experiment. J. Phys. Oceanogr., 20, 913-944.

Luyten, J. R., J. Pedlosky, and H. Stommel, 1983: The ventilated thermocline. J. Phys. Oceanogr., 13, 292-309.

Marshall, J. C., and A. J. G. Nurser, 1991: A continuosly stratified thermocline model incorporating a mixed layer of variable depth and density. J. Phys. Oceanogr., 21, 1780-1792.

McCreary, J. P., and Z. Yu., 1992: Equatorial dynamics in a $2 \frac{1}{2}$ layer model. Progress in Oceanography, Vol. 29, Pergamon, 61-132.

— torial ocean circulations: the subtropical cell. J. Phys. Oceanogr., 24, 466-497.

McPhaden, M. J., and R. A. Fine, 1988: A dynamical interpretation of the tritium maximum in the central equatorial Pacific. J. Phys. Oceanogr., 18, 1454-1457.

Pedlosky, J., 1990: The dynamics of the oceanic subtropical gyres. Science, 248, 316-322.

_ 1991a: The role of finite mixed-layer thickness in the structure of the ventilated thermocline. J. Phys. Oceanogr., 21, 10181031 .

_ $1991 \mathrm{~b}$ : The link between western boundary current and equatorial undercurrent. J. Phys. Oceanogr., 21, 1553-1558.

— 1997: Ocean Circulation Theory. Springer-Verlag, 453 pp. , and P. Robbins, 1991: The role of finite mixed-layer thickness in the structure of the ventilated thermocline. J. Phys. Oceanogr., 21, 1018-1031. 
Philander, S. G. H., 1990: El Nino, La Nina and the Southern Oscillation. Academic Press, $293 \mathrm{pp}$.

Qiao, L., and R. H. Weisberg, 1996: Tropical instability wave kinematics: Observations from the Tropical Instability Wave Experiment. J. Geophys. Res., 100, 8677-8693.

Quay, P. D., M. Stuiver, and W. S. Broeker, 1983: Upwelling rates for the equatorial Pacific Ocean derived from the delta-14 distribution. J. Mar. Res., 41, 769-792.

Rhines, P. B., and W. R. Young, 1982: A theory of wind-driven circulation 1: Mid-ocean gyres. J. Mar. Res., 40 (Suppl.), 559596.

Roemmich, D., 1987: Estimates of net transport, upwelling, and heat flux in the tropical oceans from inverse methods and related geostrophic methods. Further Progress in Equatorial Oceanography, E. Katz and K. Witte, Eds., Nova University Press, $450 \mathrm{pp}$.

Seager, R., S. E. Zebiak, and M. A. Cane, 1988: A model of the tropical Pacific sea surface temperature climatology. J. Geophys. Res., 93, 1265-1280.

Talley, L. D., 1988: Potential vorticity distribution in the North Pacific. J. Phys. Oceanogr., 18, 89-106.
Tsuchiya, M., R. Lukas, R. A. Fine, and E. Lindstrom, 1989: Source waters of the Pacific equatorial undercurrent. Progress in Oceanography, Vol. 23, Pergamon, 101-147.

Williams, R. G., 1991: The role of the mixed layer in setting the potential vorticity of the main thermocline. J. Phys. Oceanogr., 21, 1803-1814.

Wyrtki, K., 1975: Fluctuations of the dynamic topography in the Pacific Ocean. J. Phys. Oceanogr., 5, 450-459.

, and B. Kilonsky, 1984: Mean water mass and current structure during the Hawaii-to-Tahiti Shuttle Experiment. J. Phys. Oceanogr., 14, 242-254.

Zhang, R. H., and M. Endoh, 1992: A free surface general circulation model for the tropical Pacific Ocean. J. Geophys. Res., 97, $11237-11255$

_ and S. Levitus, 1996: Structure and evolution of interannual variability of the tropical Pacific upper ocean temperature. $J$. Geophys. Res., 101, 20 501-20 524.

- $[$, and 1997: Structure and cycle of decadal variability of upper ocean temperature in the North Pacific. J. Climate, 10, $710-727$. 
